\title{
Syncretism without Underspecification: The Role of Leading Forms
}

\begin{abstract}
The main goal of this article is to outline a new approach to syncretism in optimality theory, one that does not rely on the concept of underspecification taken over from grammatical theories which do not recognize constraint ranking and constraint violability. The analysis is based on a concept of morphological exponents as leading forms. Instances of syncretism can be traced back to the selection of unfaithful leading forms as a last resort to avoid paradigmatic gaps: The minimally unfaithful leading form exponent spreads to an empty paradigm cell. Three wellstudied empirical domains figure in the analysis: (i) determiner inflection in German (Bierwisch (1967), Wiese (1999)), (ii) Italian object clitics (Grimshaw (2001)), and (iii) animacy effects with noun inflection in Russian (Wunderlich (2004)).
\end{abstract}

\section{Syncretism by Underspecification}

Underspecification of morphological exponents (inflection markers) with respect to morpho-syntactic features is proposed as a general method to account for instances of syncretism (systematic homonymy) in morphological paradigms in Jakobson (1962a,b). This method is formally refined and extended in Bierwisch (1967). Underspecification is adopted as a means to derive syncretism in a variety of contemporary morphological theories, such as Distributed Morphology (see Halle \& Marantz (1993, 1994), Noyer (1992), Halle (1997), and Harley \& Noyer (2003), among others), A-Morphous Morphology (see Anderson (1992)), Paradigm Function Morphology (see Stump (2001)), Minimalist Morphology (see Wunderlich (1996, 1997b)), and Network Morphology (see Corbett \& Fraser (1993) and Baerman, Brown \& Corbett (2005)). ${ }^{1}$

As an illustration, consider the paradigm of determiner inflection in German in (1).

(1) Determiner inflection in German

\begin{tabular}{|l|c|c|c|c|}
\hline $\begin{array}{l}\text { dies } \\
\text { 'this' }\end{array}$ & MASC.SG & NEUTER.SG & FEMININE.SG & PLURAL \\
\hline \hline NOMINATIVE & er & es & e & e \\
\hline ACCUSATIVE & en & es & e & e \\
\hline DATIVE & em & em & er & en \\
\hline GENITIVE & es & es & er & er \\
\hline
\end{tabular}

This paradigm shows syncretism in abundance: There are only five different exponents for sixteen paradigm cells. ${ }^{2}$ Given an underspecification-based approach to (1), the number of exponents that need to be postulated can be significantly reduced. Such an approach works as follows. First, morpho-syntactic features (e.g., case, gender, or number features) are decomposed into combinations of more primitive features. Second, these primitive 
morpho-syntacatic features define natural classes of instantiations of grammatical categories (like case, number, person, tense, gender, etc.). Finally, an underspecification of morphological exponents with respect to these features makes reference to natural classes possible and thereby derives instances of syncretism. ${ }^{3}$

Underspecification of exponents gives rise to competition (because it is often the case that more than one exponent fits into a syntactically defined, fully specified context). The competition can be resolved by a constraint like the Subset Principle in (2). ${ }^{4}$

(2) Subset Principle

A vocabulary item $V$ is inserted into a functional morpheme $M$ iff (i) and (ii) hold:

(i) The morpho-syntactic features of $V$ are a subset of the morpho-syntactic features of $M$.

(ii) $V$ is the most specific vocabulary item that satisfies (i).

The formulation of the Subset Principle in (2) presupposes late insertion of inflectional exponents ('vocabulary items') into abstract syntactic terminal nodes ('functional morphemes'), as it is envisaged in Distributed Morphology. For the sake of concreteness, I adopt such an approach in this section. However, it should be kept in mind that this is only for expository reasons; the illustration of an underspecifiation-based approach to syncretism in (1) could just as well be carried out in any of the other morphological theories mentioned above. The Subset Principle ensures that an exponent can only be used in a given syntactic context if it is compatible with this context; i.e., the (possibly underspecified) exponent must be characterized by a subset of the morpho-syntactic features of the syntactic context. Furthermore, out of the set of exponents that satisfy the compatibility criterion, the exponent is selected that is more specific than its competitors. Specificity of exponents can be defined as in (3).

\section{(3) Specificity of vocabulary items}

A vocabulary item $V_{i}$ is more specific than a vocabulary item $V_{j}$ iff there is a class of features $\mathbb{F}$ such that (i) and (ii) hold.

(i) $V_{i}$ bears more features belonging to $\mathbb{F}$ than $V_{j}$ does.

(ii) There is no higher-ranked class of features $\mathbb{F}^{\prime}$ such that $V_{i}$ and $V_{j}$ have a different number of features in $\mathbb{F}^{\prime}$.

(3) presupposes that feature classes are ranked; some feature classes are inherently more specific than others. An exponent is more specific than another exponent if the features that are associated with it belong to the higher-ranked feature class. Where feature quality does not decide, quantity becomes relevant, with exponents that are less radically underspecified emerging as more specific (other things being equal). ${ }^{5}$

Returning to (1), it can be noted that quite a number of underspecification-based analyses of the paradigm of German determiner inflection have been proposed. Bierwisch (1967) develops an analysis in terms of underspecification; follow-up analyses based on 
underspecification and (a constraint like) the Subset Principle include Blevins (1995), Sauerland (1996), Wunderlich (1997a), Wiese (1999), Gallmann (2004), and Trommer (2005) (but see also Sternefeld (2006, 78ff) for a critique of this kind of approach). I take Wiese's approach to be representative in a number of respects (not least because it is not inherently tied to a specific theory's formalism); the following exposition is based on this analysis (adapted to the notation of Distributed Morphology).

Wiese (1999) adopts a decomposition of case features as in Bierwisch (1967); see (4-a). On this view, nominative and accusative form a natural class (that can be referred to by $[-$ obl(ique $)]$ ), as do accusative and dative $([+$ gov(erned) $])$, nominative and genitive $([-$ gov $])$, and dative and genitive $([+\mathrm{obl}])$. Furthermore, Wiese suggests a decomposition of gender and number features in German into more primitive abstract features $[ \pm$ masc(uline-type $)]$ and $[ \pm$ fem(inine-type) $([ \pm$ standard $]$ and $[ \pm$ special $]$, in his original terminology); see (4-b). Masculine and feminine genders are interpreted in the obvious way. Deviating from the etymology of the word, neuter gender is viewed as $[+$ masc,+ fem $]$; so it forms a natural class with feminine and, more importantly, with masculine gender (see $[+\mathrm{fem}]$ and $[+$ masc], respectively). The specification $[-$ masc, - fem $]$ characterizes the plural, which thus also forms a natural class with the masculine and the feminine gender (which can be referred to by the features $[-$ fem $]$ and $[-$ masc $]$, respectively). (Recall that there are no gender differentiations in the plural in German.)

(4) Feature Decomposition (Bierwisch (1967), Wiese (1999)):

a. Case

$\begin{array}{ll}\text { NOM: } & {[-\mathrm{obl},- \text { gov }]} \\ \text { ACC: } & {[- \text { obl },+ \text { gov }]} \\ \text { DAT: } & {[+ \text { obl },+ \text { gov }]} \\ \text { GEN: } & {[+ \text { obl },- \text { gov }]}\end{array}$ b. Gender/Number

MASC:

FEM:

NEUT:

PL:

$$
\begin{aligned}
& {[+ \text { masc },- \text { fem }]} \\
& {[- \text { masc },+ \text { fem }]} \\
& {[+ \text { masc },+ \text { fem }]} \\
& {[- \text { masc },- \text { fem }]}
\end{aligned}
$$

On this basis, the exponents in (1) can be assumed to bear the underspecified feature specifications in (5). ${ }^{6}$

(5) a. $[+$ masc,+ obl,+ gov $] \leftrightarrow / \mathrm{m} / 1$

(dat.masc.sg./neut.sg.)

b. $[+$ masc,$+\mathrm{obl}] \leftrightarrow / \mathrm{s} / 2$

c. $[+$ masc,+ fem $] \leftrightarrow / \mathrm{s} / 3$

(gen.masc.sg./neut.sg.)

d. $[+$ masc,+ gov $] \leftrightarrow / \mathrm{n} / 4$

(nom./acc.neut.sg.)

e. $[+$ masc $] \leftrightarrow / \mathrm{r} / 5$

(acc.masc.sg.)

f. $[+\mathrm{obl},+$ fem $] \leftrightarrow / \mathrm{r} /{ }^{6}$

(nom.masc.sg.)

g. $[+$ obl,+ gov $] \leftrightarrow / \mathrm{n} / 7$

(dat./gen.fem.sg.)

h. $[+\mathrm{obl}] \leftrightarrow / \mathrm{r} / 8$

(dat.pl.)

i. []$\leftrightarrow / \mathrm{e} /{ }^{9}$

(nom./acc.fem.sg./pl.)

According to $(5), / \mathrm{m} /{ }^{1}$ is a dative $([+\mathrm{obl},+$ gov $])$ marker for masculine and neuter contexts $([+$ masc $]) ; / \mathrm{s} /{ }^{2}$ is a general oblique $([+\mathrm{obl}])$ marker for maculine and neuter contexts 
$([+$ masc $])$, and so on; $/ \mathrm{e} /{ }^{9}$ is a radically underspecified elsewhere marker that would in principle fit anywhere. Given underspecification, a competition of exponents arises. By adopting the feature hierarchy in (6) as relevant for the notion of Specificity, all cases of marker competition are resolved by the Subset Principle.

(6) $[+$ masc $]>[+$ obl $]>[+$ fem $]>[+$ gov $]$.

The competition is shown in (7), with exponents chosen by the Subset Principle underlined, and exponents that are compatible with the syntactically determined full specification but are not specific enough added in paradigm cells.

Competition of exponents

\begin{tabular}{|c|c|c|c|c|}
\hline dies & MASC.SG & NEUT.SG & FEM.SG & PL. \\
\hline \hline NOM & $\underline{\mathrm{r}}^{5}, \mathrm{e}^{9}$ & $\underline{\mathrm{s}}^{3}, \mathrm{r}^{5}, \mathrm{e}^{9}$ & $\underline{\mathrm{e}}^{9}$ & $\underline{\mathrm{e}}^{9}$ \\
\hline ACC & $\underline{\mathrm{n}}^{4}, \mathrm{r}^{5}, \mathrm{e}^{9}$ & $\underline{\mathrm{s}}^{3}, \mathrm{n}^{4}, \mathrm{r}^{5}, \mathrm{e}^{9}$ & $\underline{\mathrm{e}}^{9}$ & $\underline{\mathrm{e}}^{9}$ \\
\hline DAT & $\underline{\mathrm{m}}^{1}, \mathrm{~s}^{2}, \mathrm{n}^{4}, \mathrm{r}^{5}, \mathrm{n}^{7}, \mathrm{r}^{8}, \mathrm{e}^{9}$ & $\underline{\mathrm{m}}^{1}, \mathrm{~s}^{2}, \mathrm{~s}^{3}, \mathrm{n}^{4}, \mathrm{r}^{5}, \mathrm{r}^{6}, \mathrm{n}^{7}, \mathrm{r}^{8}, \mathrm{e}^{9}$ & $\underline{\mathrm{r}}^{6}, \mathrm{n}^{7}, \mathrm{r}^{8}, \mathrm{e}^{9}$ & $\underline{\mathrm{n}}^{7}, \mathrm{r}^{8}, \mathrm{e}^{9}$ \\
\hline GEN & $\underline{\mathrm{s}}^{2}, \mathrm{r}^{5}, \mathrm{r}^{8}, \mathrm{e}^{9}$ & $\underline{\mathrm{s}}^{2}, \mathrm{~s}^{3}, \mathrm{r}^{5}, \mathrm{r}^{6}, \mathrm{r}^{8}, \mathrm{e}^{9}$ & $\underline{\mathrm{r}}^{6}, \mathrm{r}^{8}, \mathrm{e}^{9}$ & $\underline{\mathrm{r}}^{8}, \mathrm{e}^{9}$ \\
\hline
\end{tabular}

The analysis derives a number of instances of syncretism in a simple way: It envisages nine different exponents for determiner inflection in German. Still, since there are only five different marker forms, this leaves a few syncretisms unresolved. More specifically, there are two separate exponents for $/ \mathrm{n} /$, two exponents for $/ \mathrm{s} /$, and three exponents for $/ \mathrm{r} /$. A closer look at the literature suggests that a residue of this kind may be unavoidable in standard underspecification-based approaches, unless abstract decomposed features are introduced that capture specific combinations of case and gender as natural classes (e.g., masculine/nominative and feminine/oblique; or neuter/non-oblique and genitive/non-feminine; see Trommer (2005) for a proposal along these lines): An inventory of eight exponents seems to be the minimum; see, e.g., Blevins (1995). The reduction from nine to eight exponents can be achieved by a different characterization of two occurrences of $/ \mathrm{r} /$. Note that $/ \mathrm{r} /{ }^{6}$ and $/ \mathrm{r} /{ }^{8}$ might in principle be viewed as a single marker with a specification [ $+\mathrm{obl}$ ] in Wiese's analysis if $/ \mathrm{n} /{ }^{7}$ is explicitly restricted to plural contexts by being assigned the specification $[+\mathrm{obl},+$ gov,$(-$ masc, $)-$ fem]. One reason why Wiese does not postulate this more general / $\mathrm{r} /$ presumably is that he otherwise manages to avoid reference to negatively specified features (like $[-$ masc $]$ or $[-$ fem $]$ ). A second, arguably much more important reason is that he takes there to be independent evidence to distinguish between different kinds of homonymy in a paradigm. Let me illustrate the underlying reasoning.

As has been argued by Eisenberg $(2000,165)$ and Zifonun $(2001,39)$ for the system of determiner inflection in German, only those instances of homonymy should be viewed as instances of systematic syncretism where the identity of inflectional exponents is maintained with all material in the agreement-sensitive edge domain of an NP (i.e., pre-nominal 
material and the $\mathrm{N}$ head). The representative examples in (8) show that (with the exception of $/ \mathrm{e} /{ }^{9}$, to which I will come momentarily) for each of the exponents identified in Wiese's list in (5) as involving systematic syncretism, all NP-internal inflectional markers (i.e., including markers attached to adjectives and nouns) are identical.

(8) a. $[+$ masc,+ obl,+ gov $] \leftrightarrow / \mathrm{m} / 1$

(dat.masc.sg./neut.sg.) diesem alten Mann(e), diesem alten $\operatorname{Buch}(\mathrm{e})$

b. $\quad[+$ masc,+ obl $] \leftrightarrow / \mathrm{s} / 2$ dieses alten Mannes, dieses alten Buches

c. $\quad[+$ masc,+ fem $] \leftrightarrow / \mathrm{s} / 3$ dieses alte Buch, dieses alte Buch

d. $[+$ masc,+ gov $] \leftrightarrow / \mathrm{n} / 4$ diesen alten Mann

e. $[+$ masc $] \leftrightarrow / \mathrm{r} / 5$ 'this old man', 'this old book' dieser alte Mann (gen.masc.sg./neut.sg.) 'this old man', 'this old book' (nom./acc.neut.sg.) 'this old book' (acc.masc.sg.) 'this old man' (nom.masc.sg.) 'this old man'

f. $[+$ obl,+ fem $] \leftrightarrow / \mathrm{r} /{ }^{6}$ (dat./gen.fem.sg.) dieser alten Frau, dieser alten Frau 'this old woman'

g. $\quad[+$ obl,+ gov $] \leftrightarrow / \mathrm{n} / 7$ (dat.pl.) diesen alten Frauen 'these old women'

h. $\quad[+\mathrm{obl}] \leftrightarrow / \mathrm{r} /{ }^{8}$ (gen.pl.) dieser alten Frauen 'these old women'

i. []$\leftrightarrow / \mathrm{e} / 9$ (nom./acc.fem.sg./pl.) diese alte Frau, diese alten Frauen 'this old woman', 'these old women'

From this point of view, resolving all the remaining instances of syncretism in a principled way is not just difficult; it is actually not justified. Thus, unifying the two occurrences of /s/ (i.e., $/ \mathrm{s} /{ }^{2}, / \mathrm{s} /{ }^{3}$ ) into a single exponent with a single specification is not warranted: The determiner endings are identical, but adjectival and nominal inflection markers are not. Similar considerations apply with $/ \mathrm{n} /{ }^{4}$ and $/ \mathrm{n} /{ }^{7}$ : The syncretism can be viewed as nonsystematic because inflectional markers for the head noun in accusative masculine singular and dative plural contexts are not identical. Finally, the same goes for the remaining instance of marker homonymy that is not resolved in Wiese's analysis, viz. the three occurrences of $/ \mathrm{r} /\left(/ \mathrm{r} /{ }^{5}, / \mathrm{r} /{ }^{6}, / \mathrm{r} /{ }^{8}\right)$. (Note that it is not fully resolved in any of the other above-mentioned analyses.) This is in stark contrast to all those cases where (5) postulates a single entry, the syncretism is resolved by underspecification and feature decomposition, and the inflectional exponents are identical in the whole NP. The only exception, from this perspective, is the radically underspecified elsewhere marker $/ \mathrm{e} /{ }^{9}$ (i.e., schwa). Nonoblique feminine singular and non-oblique plural NPs can usually be distinguished with respect to the ending involved, but this can be assumed to be unproblematic for the very reason that /e/ does not have any morpho-syntactic features at all. So, on this view, one does not even want to account for all cases of homonymy by postulating a 
single, uniform entry with a non-disjunctive underspecified feature specification, and the number of entries on the list in (5) emerges as optimal. ${ }^{7}$

This sketch of Wiese's analysis of German determiner inflection may suffice as an illustration of the approach to syncretism based on underspecification (and feature decomposition). ${ }^{8}$ Given the huge number of successful analyses carried out from this perspective for a variety of different phenomena, and in a variety of different morphological theories, it seems fair to conclude that the underspecification approach is a highly successful one.

Against this background, let me now turn to the question of how syncretism can be derived in the morphological component of an optimality-theoretic grammar.

\section{Syncretism in Optimality Theory: A New Approach}

\subsection{Background}

There are various approaches to syncretism in optimality theory. Interestingly, though, the predominant type of analysis is centered around the concept of underspecification in much the same way that standard underspecification-based analyses are. ${ }^{9}$ This type of analysis has been pursued by Grimshaw (2001), Wunderlich (2001a, 2004), Trommer (2001, 2003, 2006), Ortmann (2002), and Don \& Blom (2006), among others. These approaches have to a large extent been developed independently, but they all share a common core: The morpho-syntactic features that are associated with morphological exponents can be (and often are) underspecified, which derives syncretism. The compatibility and specificity requirements of classical non-optimality-theoretic approaches based on underspecification are expressed by high-ranked constraints. All this works very much as in standard underspecification-based approaches. However, in contrast to classical underspecification-based analyses, optimality-theoretic analyses relying on underspecification typically envisage the possibility that markedness constraints may interfere and ensure that the feature structures that are to be realized by an exponent are not exactly the ones that would correspond to syntactic representations. This mechanism captures systematic syntax/morphology mismatches in a general way, which is reminiscent of the concept of impoverishment in Distributed Morphology. ${ }^{10}$ I will not discuss any of these analyses in detail at this point; but I will come back to them after having introduced the new approach based on leading forms.

\subsection{Outline of the Analysis}

There is one potential problem with underspecification-based approaches to syncretism in optimality theory: As argued by Itô et al. (1995), Artstein (1998), Bakovic (2003), and Smolensky (2006), underspecification - and especially underspecification of inputs is a dubious concept from an optimality-theoretic point of view; it is a tool that arguably belongs in a different model of grammar. Arguments against underspecification in optimality theory typically come from the domain of phonology. For instance, Smolensky $(2006,35)$ argues that underspecification should be dispensed with in optimality theory 
because (i) outputs underspecified for $\phi$ cannot truly be evaluated by optimality-theoretic constraints sensitive to the value of $\phi$, and (ii) depending upon inputs being systematically unspecified for $\phi$ is ruled out by richness of the base: In optimality theory, it is not possible to restrict inputs this way. On this view, to the extent that there are effects that look like they involve underspecification, they should be derived from standard optimalitytheoretic constraint interaction, rather than by invoking underspecification. Assuming this reasoning to be on the right track, and assuming that it carries over to morphology, a new optimality-theoretic approach to syncretism is called for, one that dispenses with underspecification. ${ }^{11}$ In what follows, I develop the outlines of such an analysis.

The analysis relies on six basic assumptions. First, there is no underspecification of exponents; this assumption is the starting point of the new approach. Second, I take paradigms to be mere epiphenomena; i.e., paradigms can be derived by application of morphological operations, and do not qualify as entities that grammatical constraints can refer to (see Bobaljik (2008) for extensive argumentation, and Anderson (1992), Aronoff (1994), Halle \& Marantz (1993), Wunderlich (1996), Stump (2001) and Baerman, Brown \& Corbett (2005) for various morphological approaches that share this assumption). Third, a crucial assumption is that not all members of a paradigm are present in the input; only some morphological exponents are. I refer to these designated exponents as leadings forms; see Wurzel (1984), Blevins (2004), Albright (2008), and Baerman (2009) on somewhat related concepts which, however, still differ significantly from the notion of leading form adopted here. ${ }^{12}$ Thus, there can be a mismatch between morphological exponents that are leading forms (and present in the input) and syntactic functions that need to be realized by morphological exponents (i.e., paradigm cells that need to be filled). Fourth, a mismatch of paradigm cells and leadings forms gives rise to syncretism: Initial gaps are filled by using "wrong" forms, i.e., unfaithful exponents (see Weisser (2007) for this basic idea), given that there (normally) cannot be any paradigmatic gaps in inflectional systems (see footnote 40 in section 4 on exceptional paradigmatic gaps that do exist). ${ }^{13}$ Fifth, mismatches between the exponent's specification and the syntactically defined target specification (i.e., the specification of the paradigm cell that needs to be filled) are minimized. However, this is not accomplished by a single minimality condition (like the Nearest Neighbour Principle in Weisser $(2007,26)$, or the Minimality principle in Lahne $(2007,11)$ ), but by a set of ranked faithfulness constraints for the features involved (as in Grimshaw (2001), Trommer (2001, 2006), Wunderlich (2004)). Sixth and finally, feature decomposition yielding natural classes of instantiations of grammatical categories (e.g., [-obl] capturing nominative and accusative in German) is needed exactly as before.

\subsection{Sample Competitions}

As an illustration of how the new approach works, let us reconsider determiner inflection in German, as in (1) above, which is repeated here as (9) (with the vocalic elements of the consonantal markers stripped off). 
Determiner inflection in German

\begin{tabular}{|l|c|c|c|c|}
\hline $\begin{array}{l}\text { dies } \\
\text { 'this' }\end{array}$ & MASC.SG & NEUTER.SG & FEMININE.SG & PLURAL \\
\hline \hline NOMINATIVE & $\mathrm{r}$ & $\mathrm{s}$ & $\mathrm{e}$ & $\mathrm{e}$ \\
\hline ACCUSATIVE & $\mathrm{n}$ & $\mathrm{s}$ & $\mathrm{e}$ & $\mathrm{e}$ \\
\hline DATIVE & $\mathrm{m}$ & $\mathrm{m}$ & $\mathrm{r}$ & $\mathrm{n}$ \\
\hline GENITIVE & $\mathrm{s}$ & $\mathrm{s}$ & $\mathrm{r}$ & $\mathrm{r}$ \\
\hline
\end{tabular}

To simplify a comparison with the new approach, it is useful to keep as many assumptions identical to an existing underspecification-based analysis as possible. For concreteness, I will rely on the system of feature decomposition of case and gender/number assumed in Wiese (1999) (see (4)): The four cases of German emerge as cross-classifications of two binary features $[ \pm$ governed $],[ \pm$ oblique $]$ (where NOM $=[-$ gov,- obl $]$, ACC $=[+$ gov, - obl $]$, DAT $=[+$ gov,+ obl $]$, and GEN $=[-$ gov,+ obl $])$; and gender and number are treated by decomposition as a single grammatical category from the point of view of morphology, by adopting the features $[ \pm$ masc $]$ and $[ \pm$ fem $]$ (where MASC $=[+$ masc,- fem $]$, FEM $=[-$ masc,+ fem $]$, NEUT $=[+$ masc,+ fem $]$, and PLURAL $=[-$ masc,- fem $])$. Given these assumptions, the nine leading forms in (10) can be postulated; note that these exponents are all fully specified for morpho-syntactic features (case, gender, and number information).

(10) Nine leading forms:

$$
\begin{aligned}
& / \mathrm{r} / 1 \leftrightarrow[+ \text { masc, }- \text { fem, }- \text { gov },- \text { obl }] \\
& / \mathrm{n} / 2 \leftrightarrow[+ \text { masc, }- \text { fem, }+ \text { gov },- \text { obl }] \\
& / \mathrm{m} / 3 \leftrightarrow[+ \text { masc },- \text { fem },+ \text { gov },+ \text { obl }] \\
& / \mathrm{s} / 4 \leftrightarrow[+ \text { masc, }- \text { fem, },- \text { gov },+ \text { obl }] \\
& / \mathrm{s} / 5 \leftrightarrow[+ \text { masc },+ \text { fem },+ \text { gov },- \text { obl }] \\
& / \mathrm{e} / 6 \leftrightarrow[- \text { masc },+ \text { fem, },- \text { gov },- \text { obl }] \\
& / \mathrm{n} / 7 \leftrightarrow[- \text { masc, }- \text { fem },+ \text { gov },+ \text { obl }] \\
& / \mathrm{r} / 8 \leftrightarrow[- \text { masc },+ \text { fem },- \text { gov },+ \text { obl }] \\
& / \mathrm{r} / 9 \leftrightarrow[- \text { masc },- \text { fem, },- \text { gov },+ \text { obl }]
\end{aligned}
$$

The nine fully specified exponents acting as leading forms in the present analysis correspond exactly to the nine underspecified exponents in Wiese's analysis; see (5) (the numbers assigned to the exponents for expository purposes are not identical, though, and the markers are accompanied by subscripts rather than superscripts). It remains to be shown how the full paradigm of determiner inflection in German can be derived. To this end, suppose that inputs for inflectional morphology comprise two items: (i) a stem that is equipped with fully specified morpho-syntactic features; and (ii) an abstract case exponent ExP that stands for the set of possible (fully specified) exponents of the inventory - in the case at hand, ExP consists of the items in (10). ${ }^{14}$ The generator GEN produces 
various competing outputs by combining the stem with exactly one item in ExP (i.e., one exponent pairing phonological and morpho-syntactic information); by convention, leaving out all other exponents in ExP does not produce a faithfulness violation. ${ }^{15}$

The main work is then done by faithfulness constraints for exponents which may have to be violated so as to fulfill an undominated constraint MATCH that requires identity of the morpho-syntactic features of a stem and the morpho-syntactic features of the exponent in the ExP that it combines with. ${ }^{16}$

(11) МАтсH:

The morpho-syntactic features of stem and exponent are identical in the output.

Undominated MATCH may trigger violations of faithfulness constraints for morphosyntactic features. It does so successfully whenever there is no leading form (i.e., no item in ExP) matching the morpho-syntactic specification of the stem chosen in the input. The faithfulness constraints for (decomposed) morpho-syntactic features on exponents are given in (12). ${ }^{17}$

(12) Faithfulness constraints for features on exponents

a. IDENTMASC:

[ \pm masc $]$ of the input must not be changed in the output on an exponent.

b. IDENTOBL:

[ $\pm \mathrm{obl}]$ of the input must not be changed in the output on an exponent.

c. IDENTFEM:

$[ \pm$ fem $]$ of the input must not be changed in the output on an exponent.

d. IDENTGOV:

[ \pm gov $]$ of the input must not be changed in the output on an exponent.

It should be emphasized here that the faithfulness constraints in (12) only concern the morpho-syntactic features of exponents; stem faithfulness must be ranked higher, and is in effect not violable in an optimal candidate in the competitions that will be discussed in this section. (However, I will come back to this in subsection 3.2, and I will argue that impoverishment(-like) operations can be modelled via optimal violations of stem faithfulness.)

The ranking of these faithfulness constraints is shown in (13). Note that this ranking implies an order of decomposed case and gender/number features that is identical to the order implicit in Wiese's (1999) feature hierarchy in (6) (which is needed to predict differences in specificity between underspecified exponents that are characterized by the same number of features); compare the feature hierarchy $[+$ masc $]>[+$ obl $]>[+$ fem $]>$ [+gov] with the ranking in (13). ${ }^{18}$

(13) Ranking:

IDENTMASC $\gg$ IDENTOBL $\gg$ IDENTFEM $\gg$ IDENTGOV 
To see how the ranking in (13) derives the full paradigm in (9), consider the incomplete version of the paradigm that consists of only leading forms.

Incomplete paradigm with leading forms only

\begin{tabular}{|l|c|c|c|c|}
\hline $\begin{array}{l}\text { dies } \\
\text { 'this' }\end{array}$ & MASC.SG & NEUTER.SG & FEMININE.SG & PLURAL \\
\hline \hline$[-$ gov,- obl $]$ & $/ \mathrm{r} / 1$ & & $/ \mathrm{e} / 6$ & \\
\hline$[+$ gov,- obl $]$ & $/ \mathrm{n} / 2$ & $/ \mathrm{s} / 5$ & & \\
\hline \hline$[+$ gov,+ obl $]$ & $/ \mathrm{m} / 3$ & & & $/ \mathrm{n} / 7$ \\
\hline$[-$ gov,+ obl $]$ & $/ \mathrm{s} / 4$ & & $/ \mathrm{r} / 8$ & $/ \mathrm{r} / 9$ \\
\hline
\end{tabular}

In the nine cases where there is a leading form, inflection can satisfy MATCH without incurring a violation of some faithfulness constraint, and optimization is trivial. However, in the remaining seven cases, there is no a priori matching exponent, and this means that faithfulness must be minimally violated in an optimal output, by changing inherent features that the exponent has in the input (as part of ExP).

In what follows, I address three of the seven cases where unfaithful outputs are required (the remaining four cases work the same way). Consider first contexts with a nominative neuter singular specification (recall that this information is assumed to be present on the stem, with high-ranked stem faithfulness constraints ensuring non-violability). As shown in (14), there is no exponent in ExP that exhibits the feature specification now required (viz., [+masc, + fem, - gov, - obl] $)$. Consequently, for this syntactically defined context (i.e., the pertinent paradigm cell), optimization selects the exponent (from the list in (10)) where adjusting the original (input) specification of morpho-syntactic features to the specification of morpho-syntactic features on the stem creates the fewest violations of high-ranked faitfulness constraints. As shown in tableau $\mathrm{T}_{1}$, the candidate with the best constraint profile is the marker $/ \mathrm{s} / 5$; therefore, output $\mathrm{O}_{5}$ is optimal. The only adjustment in feature specifications that needs to be carried out (by GEN) here is the change from $[+$ gov $]$ to $[-$ gov $]$ on the case exponent; this incurs a violation of the lowestranked faithfulness constraint IDENTGOV. ${ }^{19}$

The competing outputs $\mathrm{O}_{1}-\mathrm{O}_{4}$ and $\mathrm{O}_{6}-0_{9}$ all incur fatal violations of higher-ranked faithfulness constraints than IDENTGOV (e.g., $\mathrm{O}_{1}$, the next-best candidate, violates the higher-ranked IDENTFEM by adjusting the gender information of the exponent to that of the stem). Assuming (at least for the sake of the argument) that MATCH is in fact not part of GEN (as speculated above), GEN is free to change input feature specifications or leave them intact; but in the latter case, a fatal violation of the highest-ranked constraing MAтCH is unavoidable; compare $\mathrm{O}_{10}$ (where no feature has been changed from input to output) with $\mathrm{O}_{1} \cdot^{20}$

As a second example of how the system works, consider the case of accusative plural environments. The competition is illustrated in tableau $\mathrm{T}_{2}$. The required specification 
Tableau $T_{1}$ : Nom.Neut.Sg. contexts

\begin{tabular}{|c|c|c|c|c|c|}
\hline $\begin{array}{l}\text { Input: dies } \leftrightarrow[+ \text { masc },+ \text { fem },- \text { gov },- \text { obl }] \\
\text { ExP }\end{array}$ & MATCH & $\begin{array}{l}\text { IDENT } \\
\text { MASC }\end{array}$ & $\begin{array}{c}\text { IDENT } \\
\text { OBL }\end{array}$ & \begin{tabular}{|c|} 
IDENT \\
FEM
\end{tabular} & $\begin{array}{c}\text { IDENT } \\
\text { GOV }\end{array}$ \\
\hline $\mathrm{O}_{1}:$ dies- $\mathrm{r}_{1} \leftrightarrow[+$ masc $,-f e m,-$ gov,$-\mathrm{obl}]$ & & & & $* !$ & \\
\hline $\mathrm{O}_{2}:$ dies- $\mathrm{n}_{2} \leftrightarrow[+$ masc,- fem,+ gov,- obl $]$ & & & & $* !$ & $*$ \\
\hline $\mathrm{O}_{3}:$ dies- $\mathrm{m}_{3} \leftrightarrow[+$ masc $,-f e m,+g o v,+o b l]$ & & & $* !$ & $*$ & * \\
\hline $\mathrm{O}_{4}:$ dies-s $\mathrm{s}_{4} \leftrightarrow[+$ masc $,-f e m,-$ gov,$+o b l]$ & & & $* !$ & * & \\
\hline $\mathrm{O}_{5}:$ dies-s ${ }_{5} \leftrightarrow[+$ masc,+ fem,+ gov,$-\mathrm{obl}]$ & & & & & * \\
\hline $\mathrm{O}_{6}:$ dies- $_{6} \leftrightarrow[-$ masc,+ fem,,- gov,- obl $]$ & & $* !$ & & & \\
\hline $\mathrm{O}_{7}:$ dies- $\mathrm{n}_{7} \leftrightarrow[-$ masc $,-f e m,+$ gov,$+o b l]$ & & *! & $*$ & $*$ & $*$ \\
\hline $\mathrm{O}_{8}:$ dies- $\mathrm{r}_{8} \leftrightarrow[-$ masc,+ fem,- gov,$+o b l]$ & & $* !$ & $*$ & & \\
\hline $\mathrm{O}_{9}:$ dies $\mathrm{r}_{9} \leftrightarrow[-m a s c,-f e m,-$ gov,$+o b l]$ & & $* !$ & $*$ & * & \\
\hline $\mathrm{O}_{10}:$ dies-r ${ }_{1} \leftrightarrow[+$ masc,- fem,,- gov,- obl $]$ & $* !$ & & & & \\
\hline
\end{tabular}

on an exponent in the output is [-masc,-fem, +gov, - obl] (because, by assumption, this is the specification that shows up on the stem). Again, there is no marker that has this specification as an input property (i.e., there is no fitting leading form). The optimal exponent for this context is the exponent that adjusts feature values so as to match those of the stem by incurring violations of only the lowest-ranked faithfulness constraints; this happens to be output $\mathrm{O}_{6}$, i.e., /e/6, which as such is a marker for nominative feminine singular contexts. ${ }^{21}$

Tableau $T_{2}$ : Acc.Pl. contexts

\begin{tabular}{|c|c|c|c|c|}
\hline $\begin{array}{l}\text { Input: dies } \leftrightarrow[- \text { masc },- \text { fem },+ \text { gov },- \text { obl }] \\
\text { ExP }\end{array}$ & $\begin{array}{l}\text { IDENT } \\
\text { MASC }\end{array}$ & $\begin{array}{c}\text { IDENT } \\
\text { OBL }\end{array}$ & \begin{tabular}{c|} 
IDENT \\
FEM
\end{tabular} & $\begin{array}{l}\text { IDENT } \\
\text { GOV }\end{array}$ \\
\hline $\mathrm{O}_{1}:$ dies-r $_{1} \leftrightarrow[+$ masc,- fem,- gov,$-\mathrm{obl}]$ & *! & & & * \\
\hline $\mathrm{O}_{2}:$ dies- $\mathrm{n}_{2} \leftrightarrow[+$ masc,- fem,+ gov,- obl $]$ & $* !$ & & & \\
\hline $\mathrm{O}_{3}:$ dies- $\mathrm{m}_{3} \leftrightarrow[+$ masc,- fem,+ gov,$+o b l]$ & $* !$ & $*$ & & \\
\hline $\mathrm{O}_{4}:$ dies-s $\mathrm{s}_{4} \leftrightarrow[+$ masc,- fem,- gov,$+o b l]$ & $* !$ & $*$ & & $*$ \\
\hline $\mathrm{O}_{5}:$ dies- $\mathrm{s}_{5} \leftrightarrow[+$ masc,+ fem,+ gov,$-\mathrm{obl}]$ & $* !$ & & $*$ & \\
\hline $\mathrm{O}_{6}:$ dies- $_{6} \leftrightarrow[-$ masc $,+f e m,-g o v,-\mathrm{obl}]$ & & & $*$ & * \\
\hline $\mathrm{O}_{7}:$ dies- $\mathrm{n}_{7} \leftrightarrow[-$ masc,- fem,+ gov,$+o b l]$ & & $* !$ & & \\
\hline $\mathrm{O}_{8}:$ dies $\mathrm{r}_{8} \leftrightarrow[-$ masc $,+f e m,-g o v,+o b l]$ & & $* !$ & $*$ & * \\
\hline $\mathrm{O}_{9}:$ dies- $_{9} \leftrightarrow[-$ masc,- fem,- gov,$+o b l]$ & & $* !$ & & $*$ \\
\hline
\end{tabular}

The final case to be analyzed here in detail involves dative feminine singular contexts. The competition is shown in tableau $\mathrm{T}_{3}$. Again, this competition shows that even a single violation of low-ranked IDENTFEM can be fatal (and in doing so motivates the ranking IDENTFEM $\gg$ IDENTGOV), just like $\mathrm{T}_{1}$ did. 
Tableau $T_{3}$ : Dat.Fem.Sg. contexts

\begin{tabular}{|c|c|c|c|c|}
\hline $\begin{array}{l}\text { Input: dies } \leftrightarrow[- \text { masc },+ \text { fem },+ \text { gov },+ \text { obl }] \\
\text { ExP }\end{array}$ & \begin{tabular}{l|} 
IDENT \\
MASC
\end{tabular} & $\begin{array}{c}\text { IDENT } \\
\text { OBL }\end{array}$ & $\begin{array}{c}\text { IDENT } \\
\text { FEM }\end{array}$ & $\begin{array}{l}\text { IDENT } \\
\text { GOV }\end{array}$ \\
\hline $\mathrm{O}_{1}:$ dies $\mathrm{r}_{1} \leftrightarrow[+$ masc $,-f e m,-g o v,-o b l]$ & $* !$ & * & * & $*$ \\
\hline $\mathrm{O}_{2}:$ dies- $\mathrm{n}_{2} \leftrightarrow[+$ masc $,-f e m,+$ gov,$-o b l]$ & $* !$ & $*$ & $*$ & \\
\hline $\mathrm{O}_{3}:$ dies $-\mathrm{m}_{3} \leftrightarrow[+$ masc,- fem,+ gov,$+\mathrm{obl}]$ & $* !$ & & $*$ & \\
\hline $\mathrm{O}_{4}:$ dies-s $\mathrm{s}_{4} \leftrightarrow[+$ masc,- fem,- gov,$+\mathrm{obl}]$ & $* !$ & & $*$ & $*$ \\
\hline $\mathrm{O}_{5}:$ dies-s $\mathrm{s}_{5} \leftrightarrow[+$ masc,+ fem,+ gov,$-o b l]$ & $* !$ & $*$ & & \\
\hline $\mathrm{O}_{6}:$ dies $\mathrm{e}_{6} \leftrightarrow[-$ masc,+ fem,- gov,- obl $]$ & & $* !$ & & $*$ \\
\hline $\mathrm{O}_{7}:$ dies- $\mathrm{n}_{7} \leftrightarrow[-$ masc $,-f e m,+$ gov,+ obl $]$ & & & $* !$ & \\
\hline $\mathrm{O}_{8}:$ dies- $\mathrm{r}_{8} \leftrightarrow[-$ masc,+ fem,- gov,$+\mathrm{obl}]$ & & & & $*$ \\
\hline $\mathrm{O}_{9}:$ dies $\mathrm{r}_{9} \leftrightarrow[-$ masc,- fem,- gov,$+\mathrm{obl}]$ & & & $* !$ & * \\
\hline
\end{tabular}

As mentioned before, the remaining four competitions that are needed to close all initial paradigmatic gaps work in essentially the same way. High-ranked faithfulness constraints define strict barriers for the spreading of leading forms into empty paradigm cells, whereas low-ranked faithfulness constraints act as lines that can be crossed. The illustration in (15) captures the spreading of leading forms that documents the outcome of the seven optimization procedures (compare (14)).

Complete paradigm with spreading of leading forms

\begin{tabular}{|l|c|c||c|c|}
\hline $\begin{array}{l}\text { dies } \\
\text { 'this' }\end{array}$ & $\begin{array}{c}\text { MASC.SG } \\
{[+ \text { masc },- \text { fem }]}\end{array}$ & $\begin{array}{c}\text { NEUTER.SG } \\
{[+ \text { masc },+ \text { fem }]}\end{array}$ & $\begin{array}{c}\text { FEMININE.SG } \\
{[- \text { masc },+ \text { fem }]}\end{array}$ & $\begin{array}{c}\text { PLURAL } \\
{[- \text { masc, },-f e m]}\end{array}$ \\
\hline \hline$[-$ gov,- obl $]$ & $/ \mathrm{r} / 1$ & $\uparrow$ & $/ \mathrm{e} / 6$ & $\rightarrow$ \\
\hline$[+$ gov,- obl $]$ & $/ \mathrm{n} / 2$ & $/ \mathrm{s} / 5$ & $\downarrow$ & $\searrow$ \\
\hline \hline$[+$ gov,+ obl $]$ & $/ \mathrm{m} / 3$ & $\rightarrow$ & $\uparrow$ & $/ \mathrm{n} / 7$ \\
\hline$[-$ gov,$+\mathrm{obl}]$ & $/ \mathrm{s} / 4$ & $\rightarrow$ & $/ \mathrm{r} / 8$ & $/ \mathrm{r} / 9$ \\
\hline
\end{tabular}

To sum up so far, it has turned out that the present, underspecification-free optimalitytheoretic approach can derive instances of syncretism in the paradigm of determiner inflection in German in a straightforward way that is roughly comparable to what is the case under standard (non-optimality theoretic) underspecification-based approaches. I take this to be an interesting result in view of the assumption that there is arguably an inherent tension between underspecification and optimality theory. Before I address some general issues that this approach raises (see section 4.), I turn to the question of whether existing optimality-theoretic analyses of syncretism that rely on underspecification can be transferred to the new approach. 


\section{Reanalyses of Underspecification-Based Optimality-Theoretic Analyses}

In this section, I focus on two optimality-theoretic analyses of instances of syncretism that rely on underspecification, viz., Grimshaw's (2001) approach to Italian object clitics, and Wunderlich's (2004) approach to animacy effects with case marking in Russian.

\subsection{Grimshaw (2001) on Syncretism with Italian Object Clitics}

\subsubsection{Original Underspecification-Based Analysis}

The inventory of Italian object clitics is shown in (16). Evidently, there is a lot of syncretism that needs to be accounted for.

\section{Italian Clitics}

\begin{tabular}{|l|l|l|l|l|l|l|}
\hline & 1.SG & 2.SG & 3.SG & 1.PL & 2.PL & 3.PL \\
\hline \hline ACC & mi & ti & lo/la & ci & vi & li/le \\
\hline DAT & mi & ti & gli/le & ci & vi & - \\
\hline ACC-REF & mi & ti & si & ci & vi & si \\
\hline DAT-REF & mi & ti & si & ci & vi & si \\
\hline
\end{tabular}

In order to derive the instances of syncretism in (16), Grimshaw (2001) makes the following assumptions. First, the input is a complete morpho-syntactic feature specification. Second, the candidates are the set of pronouns in a language. ${ }^{22}$ Third, the optimal output is the clitic with the lexical representation that best matches the input specification. Fourth, candidates can be (and often are) underspecified. Against this background, the lexical entries in (17) are postulated; note that $[ \pm R]$ stands for reflexivity, and that "X" means "no specification for X".

(17) Lexical entries in the Italian clitic lexicon:

\begin{tabular}{|c|c|c|c|}
\hline fully specified clitics & & \multicolumn{2}{|l|}{ underspecified clitics } \\
\hline lo $[-\mathrm{R} 3 \mathrm{sg}$ masc acc & him/it & $\operatorname{mi}[\mathbb{R} 1 \mathrm{sg} \mathbb{G} \mathbb{C}]$ & (to) me(self) \\
\hline la $\quad[-\mathrm{R} 3 \mathrm{sg}$ fem acc $]$ & her/it & $\mathbb{R} 2 \operatorname{sg} \mathbb{G} \mathbb{C}$ & (to) you(self) \\
\hline li $\quad[-\mathrm{R} 3 \mathrm{pl}$ masc acc & them (masc) & $\mathbb{R} 1 \mathrm{pl} \mathbb{G} \mathbb{C}$ & (to) us(self) \\
\hline $\mathrm{le}_{1}[-\mathrm{R} 3 \mathrm{pl}$ fem acc $]$ & them (fem) & $\mathbb{R} 2 \mathrm{pl} \mathbb{G} \mathbb{C}$ & (to) you(self) \\
\hline gli $[-\mathrm{R} 3 \mathrm{sg}$ masc dat & to $\mathrm{him} / \mathrm{it}$ & {$[+\mathrm{R} \mathbb{P} \mathbb{N} \mathbb{C}]$} & (to) you(self) \\
\hline $\mathrm{le}_{2}[-\mathrm{R} 3 \mathrm{sg}$ fem dat & to her/it & & \\
\hline
\end{tabular}

The optimal clitic pronoun for a given fully specified input specification is then determined by a set of ranked faithfulness constraints for grammatical categories: FAITHPERS(ON), Faithnum(Ber), FaithGen(Der), FaithCase. The faithfulness constraints can (in most cases) be construed as MAX(-like) constraints that prohibit clitic pronouns as outputs which lack morpho-syntactic features that are present in the input. Consequently, each instance of feature underspecification gives rise to a faithfulness violation. Such a violation (i.e., underspecification) can only be tolerated if there is no competing clitic 
pronoun that has a better constraint profile.

As a representative example, consider the outcome of the competition for second person plural masculine accusative reflexive specifications in tableau $\mathrm{T}_{4}$ : The outputs $\mathrm{O}_{1}(s i)$ and $\mathrm{O}_{3}(l i)$, and all other exponents that are not specified as 2 . person, fatally violate the highest-ranked constraint FAITHPERS since they are either not specified at all for person, or specified for the wrong person. Thus, output $\mathrm{O}_{2}$ is chosen even though $v i$ is not specified $[+\mathrm{R}]$, which gives rise to a FAITHREFL violation. (The other output that is marked as 2 . person - viz., $t i$ - triggers an additional (and fatal) violation of FAITHNUM because it is marked as singular in the presence of a plural specification in the input.)

Tableau $T_{4}$ : 2.Pl.Masc.Acc.Refl contexts

\begin{tabular}{|c|c|c|c|c|c|}
\hline $\begin{array}{l}\text { Input: } \\
{[+\mathrm{R} 2 \mathrm{pl} \text { masc acc }]}\end{array}$ & \begin{tabular}{|l|} 
FAITH \\
PERS \\
\end{tabular} & $\begin{array}{l}\text { FAITH } \\
\text { REFL }\end{array}$ & \begin{tabular}{|c|} 
FAITH \\
NuM
\end{tabular} & $\begin{array}{c}\text { FAITH } \\
\text { GEN }\end{array}$ & \begin{tabular}{|c|} 
FAITH \\
CASE \\
\end{tabular} \\
\hline $\mathrm{O}_{1}: \mathrm{si} \leftrightarrow[+\mathrm{R} \mathbb{P} \mathbb{N} \mathbb{C}$ & $* !$ & & * & * & * \\
\hline $\mathrm{O}_{2}: \mathrm{vi} \leftrightarrow[\mathbb{R} 2 \mathrm{pl} \mathbb{G} \mathbb{C}]$ & & $*$ & & $*$ & $*$ \\
\hline $\mathrm{O}_{3}: \mathrm{li} \leftrightarrow[-\mathrm{R} 3 \mathrm{pl}$ masc acc $]$ & $* !$ & $*$ & & & \\
\hline
\end{tabular}

A second example illustrating Grimshaw's approach is shown in tableau $\mathrm{T}_{5}$. Here, the input is a third person plural masculine accusative reflexive specification. This time, the optimal output clitic is the maximally underspecified exponent $s i$ - at least, this is the case if one distinguishes between two types of faithfulness constraints for reflexivity, viz., a MAX constraint PARSEREFL that is violated by an output which is underspecified with respect to reflexivity, and a second DEP constraint FILLREFL that is violated by an output that is negatively specified for reflexivity (like $\mathrm{O}_{3}=l$, which is $[-\mathrm{R}]$ ). Without splitting up FAITHREFL into two separate constraints, $\mathrm{O}_{3}$ would wrongly be predicted to be optimal. To block $l i$, FillRefl must outrank FAithPers (which is violated by $\mathrm{O}_{1}=$ si). ${ }^{23}$

Tableau $T_{5}$ : 3.Pl.Masc.Acc.Refl contexts

\begin{tabular}{|l||c|c|c|c|c|c|}
\hline $\begin{array}{l}\text { Input: } \\
{[+\mathrm{R} 3 \mathrm{pl} \text { masc acc }]}\end{array}$ & FIll & FAith & PARse & FAith & FAith & FAith \\
\hline \hline $\mathrm{O}_{1}: \mathrm{si} \leftrightarrow[+\mathrm{R} \mathbb{P} \mathbb{N} \mathbb{G}]$ & & $*$ & & $*$ & $*$ & $*$ \\
\hline $\mathrm{O}_{2}: \mathrm{vi} \leftrightarrow[\mathbb{R} 2 \mathrm{pl} \mathbb{G} \mathbb{C}]$ & & $*$ & $* !$ & & $*$ & $*$ \\
\hline $\mathrm{O}_{3}: \mathrm{li} \leftrightarrow[-\mathrm{R} 3 \mathrm{pl}$ masc acc $]$ & $* !$ & & & & & \\
\hline
\end{tabular}

Along these lines, the paradigm in (16) can be derived from the list of exponents in (17). The approach shares a number of properties with non-optimality theoretic underspecification-based approaches to syncretism. In both cases, there is a fully specified 
matrix of morpho-syntactic features on the one hand, and a set of competing underspecified exponents on the other. The compatibility and specificity requirements that form the core of the Subset Principle also show up in the present analysis in some form: The work of the specificity requirement is done by the set of faithfulness constraints, which essentially select the minimally underspecified form as the best match, with the ranking of the constraints reminiscent of the hierarchy of feature classes postulated in some Subset Principle-based approaches (also see Trommer (2001) and above). Furthermore, these faithfulness constraints also impose a compatibility requirement since they are violated by the choice of an exponent with a non-matching feature value. As we have seen, it may in fact be necessary in some cases to separate the part of a faithfulness constraint that ensures compatibility from the part that forces specificity (viz., in the case of FILLREFL vs. PARseRefl). All in all, then, up to this point Grimshaw's approach can be viewed as belonging firmly to the classical tradition of underspecification-based analyses, the main difference being that the set of ranked constraints provides a somewhat more flexible way of resolving the competition of exponents than is available in standard, non-optimality theoretic models.

Given that the approach crucially relies on underspecification, the question arises of whether an underspecification-free version along the lines sketched in the previous section is available. ${ }^{24}$

\subsubsection{Revised Analysis without Underspecification}

This is indeed the case. The revised inventory of Italian object clitics in (18) provides fully specified entries for all existing exponents. ${ }^{25}$

(18) Leading forms in the Italian clitic lexicon, without underspecification:

$$
\begin{aligned}
& \text { lo } \leftrightarrow[- \text { refl, }-1,-2,- \text { pl,--fem, + gov, }- \text { obl }] \quad \text { him/it } \\
& \text { la } \leftrightarrow[- \text { refl, }-1,-2-\text { pl },+ \text { fem },+ \text { gov },- \text { obl }] \text { her } / \text { it } \\
& \text { li } \leftrightarrow[- \text { refl, }-1,-2,+ \text { pl, }- \text { fem },+ \text { gov },- \text { obl }] \text { them }(,-,+ \text { fem }) \\
& \mathrm{le}_{1} \leftrightarrow[- \text { refl, }-1,-2,+ \text { pl, }+ \text { fem },+ \text { gov },- \text { obl }] \text { them }(,+ \text { fem }) \\
& \text { gli } \leftrightarrow[- \text { refl, }-1,-2,- \text { pl, }- \text { fem },+ \text { gov },+ \text { obl }] \text { to him/it } \\
& \mathrm{le}_{2} \leftrightarrow[- \text { refl, }-1,-2,- \text { pl },+ \text { fem },+ \text { gov },+ \text { obl }] \text { to her } / \text { it } \\
& \text { mi } \leftrightarrow[- \text { refl, }+1,-2,- \text { pl, +fem, +gov, },- \text { obl }] \text { (to) me(self) } \\
& \text { ti } \leftrightarrow[- \text { refl, }-1,+2,- \text { pl },+ \text { fem },+ \text { gov },- \text { obl }] \text { (to) you(self) } \\
& \text { ci } \leftrightarrow[- \text { refl, }+1,-2,+ \text { pl },+ \text { fem },+ \text { gov },- \text { obl }] \text { (to) us(self) } \\
& \text { vi } \leftrightarrow[- \text { refl, }-1,+2,+ \text { pl },+ \text { fem },+ \text { gov },- \text { obl }] \text { (to) you(self) } \\
& \text { si } \leftrightarrow[+ \text { refl, }-1,-2,- \text { pl },+ \text { fem },+ \text { gov },- \text { obl }] \text { (to) you(self) }
\end{aligned}
$$

These lexical entries give rise to the incomplete version of the paradigm of Italian object clitics in (19). 
Incomplete paradigm with leading forms only

\begin{tabular}{|l|c|l|l|l|l|l|}
\hline & 1.SG & 2.SG & 3.SG & 1.PL & 2.PL & $3 . \mathrm{PL}$ \\
\hline \hline ACC & $/ \mathrm{mi} /$ & $/ \mathrm{ti} /$ & $/ \mathrm{lo} / / \mathrm{la} /$ & $/ \mathrm{ci} /$ & $/ \mathrm{vi} /$ & $/ \mathrm{li} /, / \mathrm{le} /$ \\
\hline DAT & & & $/ \mathrm{gli} / / / \mathrm{le} /$ & & & \\
\hline ACC-REF & & & $/ \mathrm{si} /$ & & & \\
\hline DAT-REF & & & & & & \\
\hline
\end{tabular}

The only thing that remains to be done in order to reconstruct Grimshaw's analysis in an underspecification-free approach is to introduce a system of ranked faithfulness constraints that correctly predicts how the holes in (19) are filled. As it turns out, it suffices to reinterpret Grimshaw's MAX constraints as IDENT constraints (with underspecification not being an option, Grimshaw's DeP constraint FiLlRefl can be dispensed with). The original ranking can be maintained: IdentPers (= IdEnt $[ \pm 1]$, Ident $[ \pm 2]) \gg \operatorname{IdEnTREFL~} \gg$ IdENTNum $\gg$ IDENTCASE (= IDENTOBL, in the cases considered here) ${ }^{26}$ Under these assumptions, Grimshaw's (2001) underspecification-based analysis can be transferred to an underspecification-free analysis. ${ }^{27}$ An undominated IDENTPERs ensures that a clitic can never spread into a paradigm cell which has a different person specification. A lowranked IDENTCASE correctly predicts that accusative clitics are regularly used as dative clitics. Similarly, a low-ranked IDENTGEn makes it possible to use clitics specified as feminine in masculine contexts (had the basic gender specification in (18) been different, this would have been the other way around). IDENTREFL can be violated, but only if this is the only way to satisfy IDENTPERs (this implies that si cannot spread into first or second person reflexive contexts).

To give a few examples of how the revised system works, let us look first at the competition in second person plural masculine accusative reflexive contexts; see tableau $\mathrm{T}_{6}$ (compare tableau $\mathrm{T}_{4}$ above). ${ }^{28}$ The assumption here is that the input contains an abstract pronominal stem (bearing the categorial feature D, among other things) providing the target specification, and a category ExP that includes the set of clitic exponents with potentially conflicting specifications of morpho-syntactic features. ${ }^{29}$ As before, an undominated MATCH (that is left out in the tableaux, as before) triggers adjustments of the competing clitic exponents to the specification of the abstract pronominal head (also cf. footnote 19 on features of exponents that are set in italics).

As shown in tableau $\mathrm{T}_{6}$, the optimal output vi incurs non-fatal violations of IDENTREFL and IDENTGEN. The latter violation is an artefact of the theory (because one could just as well have assumed that $v i$ is marked [-fem] in the input). The former violation could only be avoided by resorting to si, which is inherently marked as $[+$ refl]; however, si triggers a violation of the higher-ranked constraint IDENTPERS in this environment. Thus, si can never spread into non-third person reflexive paradigm cells.

The second example discussed above involves third person plural masculine accusative reflexive contexts. The competition is illustrated in tableau $\mathrm{T}_{7}$. 
Tableau $T_{6}$ : 2.Pl.Masc.Acc.Refl contexts reconsidered

\begin{tabular}{|c|c|c|c|c|c|}
\hline $\begin{array}{l}\text { Input: Pron } \leftrightarrow[+ \text { refl },-1,+2,+ \text { pl },- \text { fem },+ \text { gov },- \text { obl }] \\
\text { ExP }\end{array}$ & $\begin{array}{r}\text { IDENT } \\
\text { PERS }\end{array}$ & $\begin{array}{c}\text { IDENT } \\
\text { REFL }\end{array}$ & $\begin{array}{c}\text { IDENT } \\
\text { NuM }\end{array}$ & $\begin{array}{c}\text { IDENT } \\
\text { GEN }\end{array}$ & $\begin{array}{l}\text { IDENT } \\
\text { CASE }\end{array}$ \\
\hline $\mathrm{O}_{1}:$ lo $\leftrightarrow[-r e f l,-1,-2,-p l,-$ fem,+ gov,- obl $]$ & $* !$ & $*$ & $*$ & & \\
\hline $\mathrm{O}_{2}:$ la $\leftrightarrow[-r e f l,-1,-2,-p l,+f e m,+$ gov,- obl $]$ & $* !$ & $*$ & $*$ & $*$ & \\
\hline $\mathrm{O}_{3}:$ li $\leftrightarrow[-r e f l,-1,-2,+$ pl,- fem,+ gov,- obl $]$ & $* !$ & * & & & \\
\hline $\mathrm{O}_{4}: \mathrm{le}_{1} \leftrightarrow[-r e f l,-1,-2,+\mathrm{pl},+$ fem $,+\mathrm{gov},-\mathrm{obl}]$ & $* !$ & * & & $*$ & \\
\hline $\mathrm{O}_{5}:$ gli $\leftrightarrow[-r e f l,-1,-2,-p l,-$ fem,+ gov,$+o b l]$ & $* !$ & $*$ & $*$ & & $*$ \\
\hline $\mathrm{O}_{6}: \mathrm{le}_{2} \leftrightarrow[-r e f l,-1,-2,-p l,+f e m,+$ gov,$+o b l]$ & $* !$ & $*$ & $*$ & $*$ & $*$ \\
\hline $\mathrm{O}_{7}: \mathrm{mi} \leftrightarrow[-r e f l,+1,-2,-p l,+f e m,+$ gov,$-\mathrm{obl}]$ & $* ! *$ & * & $*$ & $*$ & \\
\hline $\mathrm{O}_{8}: \mathrm{ti} \leftrightarrow[-r e f l,-1,+2,-p l,+f e m,+$ gov,$-\mathrm{obl}]$ & & $*$ & $* !$ & & $*$ \\
\hline $\mathrm{O}_{9}:$ ci $\leftrightarrow[-r e f l,+1,-2,+\mathrm{pl},+f e m,+$ gov,$-\mathrm{obl}]$ & $* ! *$ & $*$ & & * & \\
\hline $\mathrm{O}_{10}: \mathrm{vi} \leftrightarrow[-r e f l,-1,+2,+\mathrm{pl},+$ fem,+ gov,$-\mathrm{obl}]$ & & * & & $*$ & \\
\hline $\mathrm{O}_{11}:$ si $\leftrightarrow[+$ refl $,-1,-2,-p l,+$ fem,+ gov,- obl & $* !$ & & $*$ & * & \\
\hline
\end{tabular}

The reflexive clitic si is optimal for all third person reflexive contexts because competing clitics will have to fatally violate either IDENTREFL (if they are specified as third person) or both IDENTREFL and IDENTPERS (if they are specified as first or second person). Note in particular that si is also correctly predicted to spread into third person plural dative reflexive contexts. Here it will incur an additional violation of IDENTCASE, but this is unproblematic since all competitors (including the clitics specified as dative, i.e., [+gov, +obl]) violate higher-ranked IDEntREFL or IDENTPERs.

Consider finally the case of first person masculine dative non-reflexive contexts. The competition is illustrated in tableau $\mathrm{T}_{8}$. The initial paradigmatic gap cannot be filled by a non-first person exponent because of the undominated constraint IDENTPERs. Among others, this excludes the two clitics which have a dative specification in the input (viz., $\left.g l i, l e_{2}\right)$, and which therefore qualify as the only candidates that respect IDENTCASE. Consequently, only $m i$ and $c i$ remain; both exponents are marked $[+1,-2]$. However, in this context, $c i$ is in fact harmonically bounded by $m i$, due to an additional violation of IDENTNum. Note that even if there were a first person plural clitic $\alpha$ with an inherent dative specification, the present ranking would not permit it to be optimal in the environment in $\mathrm{T}_{8}$. Given the partial ranking IDENTNum $\gg$ IDENTCASE, the system predicts spreading of $m i$ (in violation of IDENTCASE), not spreading of $\alpha$ (in violation of IDENTNUM).

Along these lines, the full paradigm of object clitics in Italian can be derived on the basis of the leading forms in (18) in much the same way as in Grimshaw's (2001) underspecification-based approach. ${ }^{30}$ 
Tableau $T_{7}$ : 3.Pl.Masc.Acc.Refl contexts reconsidered

\begin{tabular}{|c|c|c|c|c|c|}
\hline $\begin{array}{l}\text { Input: Pron } \leftrightarrow[+ \text { refl },-1,-2,+ \text { pl },- \text { fem },+ \text { gov },- \text { obl }] \\
\text { ExP }\end{array}$ & \begin{tabular}{c|} 
IDENT \\
PERS
\end{tabular} & $\begin{array}{c}\text { IDENT } \\
\text { REFL }\end{array}$ & $\begin{array}{c}\text { IDENT } \\
\text { NuM }\end{array}$ & \begin{tabular}{c|} 
IDENT \\
GEN
\end{tabular} & $\begin{array}{l}\text { IDENT } \\
\text { CASE }\end{array}$ \\
\hline 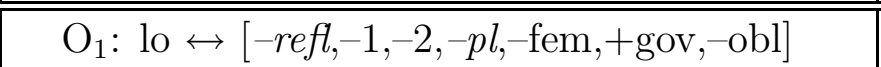 & & *! & $\bar{*}$ & & \\
\hline $\mathrm{O}_{2}:$ la $\leftrightarrow[-r e f l,-1,-2,-p l,+f e m,+$ gov,- obl $]$ & & $* !$ & $*$ & * & \\
\hline $\mathrm{O}_{3}: \mathrm{li} \leftrightarrow[-r e f l,-1,-2,+\mathrm{pl},-$ fem,+ gov,$-\mathrm{obl}]$ & & $* !$ & & & \\
\hline $\mathrm{O}_{4}: \mathrm{le}_{1} \leftrightarrow[-r e f l,-1,-2,+\mathrm{pl},+$ fem,+ gov,$-\mathrm{obl}]$ & & $* !$ & & * & \\
\hline $\mathrm{O}_{5}:$ gli $\leftrightarrow[-r e f l,-1,-2,-p l,-$ fem,+ gov,$+o b l]$ & & $* !$ & $*$ & & $*$ \\
\hline $\mathrm{O}_{6}: \mathrm{le}_{2} \leftrightarrow[-r e f l,-1,-2,-p l,+f e m,+$ gov,$+o b l]$ & & $* !$ & $*$ & $*$ & $*$ \\
\hline $\mathrm{O}_{7}: \mathrm{mi} \leftrightarrow[-r e f l,+1,-2,-p l,+f e m,+$ gov,$-\mathrm{obl}]$ & $* !$ & * & $*$ & * & \\
\hline $\mathrm{O}_{8}:$ ti $\leftrightarrow[-r e f l,-1,+2,-p l,+$ fem,+ gov,- obl $]$ & $* !$ & * & $*$ & $*$ & \\
\hline $\mathrm{O}_{9}:$ ci $\leftrightarrow[-r e f l,+1,-2,+\mathrm{pl},+$ fem,+ gov,- obl $]$ & $* !$ & * & & * & \\
\hline $\mathrm{O}_{10}:$ vi $\leftrightarrow[-r e f l,-1,+2,+\mathrm{pl},+$ fem,+ gov,$-\mathrm{obl}]$ & $* !$ & * & & $*$ & \\
\hline $\mathrm{O}_{11}:$ si $\leftrightarrow[+$ refl, $-1,-2,-p l,+$ fem,+ gov,- obl & & & * & $*$ & \\
\hline
\end{tabular}

\subsection{Wunderlich (2004) on Syncretism in the Russian Declension}

\subsubsection{Original Underspecification-Based Analysis}

Wunderlich (2004) sets out to derive instances of case syncretism with Russian nouns; in particular, he is concerned with animacy effects in the choice of accusative exponents in the first (masculine) declension and in the plural. The analysis is developed in the framework of Minimalist Morphology (see Wunderlich (1996, 1997b)), an approach to inflectional morphology that relies on underspecification (see above). However, standard Minimalist Morphology is here (as in other recent works) enriched by optimization procedures.

The empirical domain is the nominative/accusative/genitive subparadigm of the four Russian declensions. The singular forms are shown in (20).

Russian nouns with animacy split in forms that are used in accusative contexts

\begin{tabular}{|l||c|c|c|c|c|c|c|}
\hline \multicolumn{1}{|c||}{} & \multicolumn{4}{c|}{ inanimates } & \multicolumn{3}{c|}{ animates } \\
\cline { 2 - 7 } & class 2 & class 3 & class 1 & class 4 & class 2 & class 3 & class 1 \\
\hline & fem. & fem. & masc. & neut. & fem. & fem. & masc. \\
& 'map' & 'door' & 'table' & 'word' & 'squirrel' & 'mother' & 'student' \\
\hline N.sg. & kárt-a & dver' & stol & slov-o & bélk-a & mat' & studént \\
A.sg. & kárt-u & dver' & stol & slov-o & bélk-u & mat' & studént-a \\
G.sg. & kárt-y & dvér-i & stol-á & slov-á & bélk-i & máter-i & studént-a \\
\hline N.pl. & kárt-y & dvér-i & stol-ýy & slov-á & bélk-i & máter-i & studént-y \\
A.pl. & kárt-y & dvér-i & stol-ýy & slov-á & bélok & máter-ej & studént-ov \\
G.pl. & kart & dver-éj & stol-óv & slov & bélok & máter-ej & studént-ov \\
\hline
\end{tabular}

Wunderlich (2004) assumes a decomposition of case features according to which nomi- 
Tableau $T_{8}$ : 1.Sg.Masc.Dat.Nonrefl contexts

\begin{tabular}{|c|c|c|c|c|c|}
\hline $\begin{array}{l}\text { Input: Pron } \leftrightarrow[- \text { refl },+1,-2,- \text { pl, }- \text { fem },+ \text { gov },+ \text { obl }] \\
\text { ExP }\end{array}$ & \begin{tabular}{|c|} 
IDENT \\
PERS
\end{tabular} & \begin{tabular}{c|} 
IDENT \\
REFL
\end{tabular} & $\begin{array}{c}\text { IDENT } \\
\text { NuM }\end{array}$ & \begin{tabular}{c|} 
IDENT \\
GEN
\end{tabular} & $\begin{array}{l}\text { IDENT } \\
\text { CASE }\end{array}$ \\
\hline $\mathrm{O}_{1}:$ lo $\leftrightarrow[-$ refl, $,-1,-2,-$ pl, - fem,+ gov,$-o b l]$ & $* !$ & & & & * \\
\hline $\mathrm{O}_{2}:$ la $\leftrightarrow[-$ refl $,-1,-2,-$ pl $,+f e m,+$ gov,$-o b l]$ & $* !$ & & & * & * \\
\hline $\mathrm{O}_{3}:$ li $\leftrightarrow[-$ refl $,-1,-2,+p l,-$ fem,+ gov,$-o b l]$ & $* !$ & & $*$ & & $*$ \\
\hline $\mathrm{O}_{4}: \mathrm{le}_{1} \leftrightarrow[-\mathrm{refl},-1,-2,+p l,+$ fem,+ gov,$-o b l]$ & $* !$ & & $*$ & * & $*$ \\
\hline $\mathrm{O}_{5}:$ gli $\leftrightarrow[-$ refl $,-1,-2,-$ pl,- fem,+ gov,+ obl $]$ & $* !$ & & & & \\
\hline $\mathrm{O}_{6}: \mathrm{le}_{2} \leftrightarrow[-\mathrm{refl},-1,-2,-\mathrm{pl},+$ fem $,+\mathrm{gov},+\mathrm{obl}]$ & $* !$ & & & * & \\
\hline $\mathrm{O}_{7}: \mathrm{mi} \leftrightarrow[-\mathrm{refl},+1,-2,-\mathrm{pl},+$ fem $,+\mathrm{gov},-\mathrm{obl}]$ & & & & $*$ & * \\
\hline $\mathrm{O}_{8}: \mathrm{ti} \leftrightarrow[-\mathrm{refl},-1,+2,-\mathrm{pl},+$ fem,+ gov,$-\mathrm{obl}]$ & *!* & & & * & * \\
\hline $\mathrm{O}_{9}:$ ci $\leftrightarrow[-$ refl $,+1,-2,+p l,+$ fem, + gov,$-o b l]$ & & & $* !$ & * & * \\
\hline $\mathrm{O}_{10}:$ vi $\leftrightarrow[-\mathrm{refl},-1,+2,+p l,+$ fem $,+\mathrm{gov},-o b l]$ & $* ! *$ & & * & $*$ & * \\
\hline $\mathrm{O}_{11}:$ si $\leftrightarrow[+r e f l,-1,-2,-\mathrm{pl},+$ fem,+ gov,$-o b l]$ & $* !$ & $*$ & & * & * \\
\hline
\end{tabular}

native case is left without a specification altogether; accusative case bears the features $[+\mathrm{hr}],[\mathrm{v}]$; and genitive case is specified as $[+\mathrm{hr}],[\mathrm{n}]$. Here, "[+hr]" stands for "there is a higher role", i.e., the case is assigned to an internal argument in the presence of an external argument; "v" and "n" stand for "(prototypically) assigned by verbs" and "(prototypically) assigned by nouns", respectively. Thus, accusative and genitive form a natural class captured by $[+\mathrm{hr}]$, and since the nominative is featureless, it cannot be referred to by any exponent. The list of (underspecified) exponents that Wunderlich postulates for genitive and accusative singular in (20) is given in (21).

(21) a. $\left./-\mathrm{u} /,(+\mathrm{hr})_{V} / \mathrm{a}\right]$

acc.sg (class 2)

b. $\left.\left./-\mathrm{y} /,(+\mathrm{hr})_{N} / \mathrm{a}\right] \vee \mathrm{PAL}\right]$

c. $/-\mathrm{a} /,+\mathrm{hr} / \mathrm{C}] \vee \mathrm{o}]$

gen.sg (class $2 \& 3$ ) acc/gen.sg (class $1 \& 4$ )

Some comments on notation are in order here. First, as before, the / / notation indicates that the exponents are abstract (underlying) forms that may be subject to further change by phonological and morpho-phonological rules (deriving, e.g., vowel alternations in hard and soft consonantal environments). Second, Wunderlich assumes that the nominative endings $-a$ and $-o$ are not in fact case exponents, but rather genuine theme vowels that inherently belong to the stem, and that are dropped in non-nominative cases $(-a)$, or in non-nominative/non-accusative cases $(-o)$. The nominative endings of stems are assumed to encode inflection class; i.e., "a]" stands for inflection class 2, "o]" stands for inflection class 4, "PAL]" stands for inflection class 3 (where all stems end in a palatalized consonant), and "C]" stands for inflection class 1 (where all stems end in a consonant, which, however, may also be a soft, i.e., palatalized, one). ${ }^{31}$ The paradigm that we want to derive from (21) for nominative, accusative, and genitive contexts with the first three inflection classes is given in (22) (see Wunderlich $(2004,382)$ ). 
Lexical entries for some Russian case affixes in the singular

\begin{tabular}{|c|c|c|c|c|c|c|}
\hline & \multicolumn{3}{|c|}{ inanimates } & \multicolumn{3}{|c|}{ animates } \\
\hline & class 2 & class 3 & class 1 & class 2 & class 3 & class 1 \\
\hline & 'map' & 'door' & 'table' & 'squirrel' & 'mother' & 'student' \\
\hline N.sg. & a] & \multirow[t]{2}{*}{ PAL] } & & a] & \multirow[t]{2}{*}{ PAL] } & \\
\hline A.sg. & $/-\mathrm{u} /,(+\mathrm{hr})_{V}$ & & & $/-\mathrm{u} /,(+\mathrm{hr})_{V}$ & & \multirow[b]{2}{*}{$/-\mathrm{a} /,+\mathrm{hr}$} \\
\hline G.sg. & $\mid-\mathrm{y} /,(+\mathrm{h}$ & $N$ & $/-\mathrm{a} /,+\mathrm{hr}$ & $\mid-\mathrm{y} /,(+$ & $\mathrm{nr})_{N}$ & \\
\hline
\end{tabular}

However, a comparison of (21) and (22) reveals that the distribution of exponents over paradigm cells in (22) is not yet fully correct: To wit, the animacy-based alternation between /-a/ and zero marking in the accusative of inflection class 1 is not yet accounted for. As it stands, /-a/ should show up with inanimate stems in the accusative of inflection class 1 in exactly the same way that it shows up with animates. Wunderlich argues that the animacy effect can be derived without invoking a special feature [ \pm animate] in the specification of exponents, by adopting a system of violable constraints in an optimalitytheoretic approach. The central constraints that he suggests, as well as their ranking, are given in (23).

(23) a. $*(+\mathrm{hr}) / V$ inanim

b. $\operatorname{MAx}(+\mathrm{hr})$

c. Ranking of the constraints: $*(+\mathrm{hr}) / V$ inanim $\gg \operatorname{MAx}(+\mathrm{hr}) \gg *(+\mathrm{hr}) /{ }_{V}$ anim

In accusative contexts with inanimate stems, there is a conflict between the markedness constraint $*(+h r) / v$ inanim, which blocks the realization of the case feature $[+\mathrm{hr}]$ in accusative contexts of inanimate noun stems, and $\operatorname{MAx}(+h r)$, which demands a realization of just this feature. The ranking in (23-c) leads to a suppression of this feature in the optimal output, and this makes it impossible for the (otherwise expected) marker /-a/ to show up. In contrast, in accusative contexts with animate stems, * $(+h r) / v$ inanim is satisfied vacuously by all candidates; hence, the lower-ranked MAx $(+h r)$ springs into action and ensures that $[+\mathrm{hr}]$ is realized in the output. A yet lower-ranked constraint $*(+h r) / v$ anim that can be postulated for reasons of symmetry alone must be violated in this context, given the ranking in (23-c). This is the core of the analysis of the animacy effect with the first declension in the singular in Russian. There is a bit more that must be said to derive the paradigm in (22) in full. To ensure that an animacy effect does not show up with the (predominantly) feminine inflection class 2, a high-ranked constraint $\operatorname{MAx}(+h r) /-p l, a]$ is adopted which makes it possible that the exponent /-u/ (which is specified for $[+\mathrm{hr}]$ ) can appear, i.e., that the accusative marker for the second declension can in fact show up in (inanimate) accusative second declension contexts; see (24-a). In addition, Wunderlich's (2004) analysis relies on two high-ranked constraints that capture the specificity and compatibility requirements of the Subset Principle in a 
fairly straightforward way; see (24-bc).

(24) a. $\operatorname{MAx}(+\mathrm{hr}) /-\mathrm{pl}, \mathrm{a}]$

b. SPECIFICITY

Choose the affix with the more specific selectional information.

c. Compatibility

Do not insert a form in a context in which the categorial specifications are incompatible.

The overall ranking of the constraints is shown in (25).

$$
\text { Spec, Comp, } \operatorname{Max}(+\mathrm{hr}) /-\mathrm{pl}, \mathrm{a}] \gg *(+\mathrm{hr}) / V-\operatorname{anim} \gg \operatorname{Max}(+\mathrm{hr})
$$

As noted by Wunderlich $(2004,384)$, the ranking predicts the following: "Realize both accusative and genitive, unless inanimate nouns occur in accusative contexts, excluding class 2 nouns (ending in - $a$, where there exists the accusative morpheme /-u/)." To see how the system works, consider first the case of inanimate nouns of inflection classes 1 (with an animacy effect) and 2 (without an animacy effect); the competitions are illustrated by tableaux $\mathrm{T}_{9}$ and $\mathrm{T}_{10}$, respectively. The important difference between inflection classes 1 and 2 in this domain is that the violation of $*(+h r) / V$ inanim incurred by exponents that are marked $[+\mathrm{hr}]$ is fatal with class 1 stems and non-fatal with class 2 stems (because of the higher-ranked, highly specific faithfulness constraint $\operatorname{MAx}(+h r) /-p l, a])$.

Tableau $T_{9}$ : Accusative singular exponents with inanimate class 1 stems

\begin{tabular}{|c|c|c|c|c|}
\hline & $\begin{array}{c}\text { SPEC । COMP } \\
\text { । }\end{array}$ & $\begin{array}{l}\text { | MAx }(+\mathrm{hr}) / \\
\text { । }\end{array}$ & $\begin{array}{c}*(+\mathrm{hr}) / V \\
\text {-anim }\end{array}$ & $\operatorname{MAx}(+\mathrm{hr})$ \\
\hline wel stol & I & I & & * \\
\hline$\overline{\text { stol-a }}$ & 1 & I & $* !$ & \\
\hline stol-y & I $* !$ & I & & \\
\hline
\end{tabular}

Tableau $T_{10}$ : Accusative singular exponents with inanimate class 2 stems

\begin{tabular}{|c|c|c|c|c|}
\hline & $\begin{array}{c}\text { SPEC । COM } \\
\text { । }\end{array}$ & $\begin{array}{l}\operatorname{MAx}(+\mathrm{hr}) / \\
\quad-\mathrm{pl}, \mathrm{a}]\end{array}$ & $\begin{array}{c}*(+\mathrm{hr}) / V \\
\text {-anim }\end{array}$ & $\operatorname{MAX}(+\mathrm{hr})$ \\
\hline karta & I & $* !$ & & * \\
\hline kart-y & । $\quad * !$ & 1 & & \\
\hline kart-u & । & 1 & * & \\
\hline
\end{tabular}

In accusative contexts with animate stems of inflection classes 1 and $2, *(+h r) / V$ inanim is irrelevant. Therefore, a $[+\mathrm{hr}]$-marked exponent is optimal throughout; see tableau $\mathrm{T}_{11}$ (for class 1 environments). 
Tableau $T_{11}$ : Accusative singular exponents with animate class 1 stems

\begin{tabular}{|c|c|c|c|c|}
\hline & $\begin{array}{c}\text { SPEC । COMP } \\
\text { । }\end{array}$ & $\begin{array}{l}\text { | } \operatorname{Max}(+\mathrm{hr}) / \\
\text { । }-\mathrm{pl}, \mathrm{a}]\end{array}$ & $\begin{array}{c}*(+\mathrm{hr}) / \mathrm{V} \\
\text {-anim }\end{array}$ & $\operatorname{MAx}(+\mathrm{hr})$ \\
\hline student & | & 1 & & $* !$ \\
\hline ar student-a & । & । & & \\
\hline student-y & ! *! & 1 & & \\
\hline
\end{tabular}

Finally, note that the genitive exponent /-y/ (for classes 2 and 3) can never become optimal in accusative contexts, not even with animate stems, because it is not underspecified (it is specified as $[+h r], \mathbf{n}$, not simply as $[+h r]$ ); therefore, it violates the compatibility requirement in this environment. This is shown in tableau $\mathrm{T}_{12}$.

Tableau $T_{12}$ : Accusative singular exponents with animate class 3 stems

\begin{tabular}{|c|c|c|c|c|}
\hline & $\begin{array}{c}\text { SPEC । COMP } \\
\text { । }\end{array}$ & $\begin{array}{l}\text { | } \operatorname{MAx}(+\mathrm{hr}) / \\
\mid-\mathrm{pl}, \mathrm{a}]\end{array}$ & $\begin{array}{c}*(+\mathrm{hr}) / V \\
- \text { anim }\end{array}$ & $\operatorname{MAx}(+h r)$ \\
\hline mat' & 1 & I & & $*$ \\
\hline mater'-i & ! *! & 1 & & \\
\hline
\end{tabular}

To sum up so far, the analysis derives instances of both nominative/accusative syncretism and accusative/genitive syncretism. The latter is accounted for by assuming that accusative and genitive form a natural class (encoded by $[+\mathrm{hr}]$ ) that exponents can refer to, via underspecification of case information; the former cannot be traced back to underspecification, however: Either there is no exponent available for these two contexts at all, or the use of the "right" exponent is blocked by a high-ranked markedness constraints, which effectively produces a retreat to the general case. In this latter respect, the analysis is similar to impoverishment approaches.

Again, at this point the question arises of whether the gist of Wunderlich's analysis can be captured in an optimality-theoretic approach that does rely on underspecification; and again, the answer is affirmative.

\subsubsection{Revised Analysis without Underspecification}

For reasons of overall coherence, I will adapt aspects of Wunderlich's (2004) analysis that are of secondary importance in the present context to the current set of assumptions, as I did in the case of Grimshaw (2001). More specifically, I will replace Wunderlich's decomposed case features with the system adopted above; and I will replace his way of encoding inflection class information by listing the (ending of the) nominative forms with a feature-based mechanism as well. However, I will leave all crucial aspects of the original analysis intact. ${ }^{32}$

Suppose that there are three primitive, binary case features whose cross-classification yields the six cases of Russian (plus two surplus cases which arguably are not used - 
though the existence of separate, "second" genitive and locative cases in Russian has sometimes been argued for): In addition to Bierwisch's (1967) [ \pm gov] and [ $\pm \mathrm{obl}]$, there is a third feature $[ \pm \operatorname{subj}($ ect $)]$; see Wiese (2003b) on Latin and Wiese (2003a) on Russian (though not Wiese (2004) on Russian, which uses a different, somewhat less abstract case feature system). Nominative, accusative, and genitive can be defined as in (26-a); note that on this view, both nominative and accusative, and genitive and accusative form a natural class. ${ }^{33}$ Next, in contrast to Wunderlich (2004), I assume that inflection class features are necessary. Furthermore, there are many instances of syncretism that span inflection classes; these cases of trans-paradigmatic syncretism can be derived by recourse to natural classes of inflection classes; such natural classes of inflection classes, in turn, can be produced by decomposing inflection class features, and permitting marker reference to underspecified inflection class information (see Müller (2004) on Russian, and Alexiadou \& Müller (2008) for other languages and general considerations). This way, disjunctions in marker entries that are needed in Wunderlich's approach can be dispensed with (see, e.g., the references to "a] $\vee \mathrm{PAL}$ ]" (i.e., class 2 or class 3 ) and "C] $\vee$ o]" (i.e., class 1 or class 4 ) in (21). The system of decomposed inflection class features is shown in (26-b).

(26) Feature decomposition of Russian cases and inflection classes:

\section{a. Case}

NOM:

ACC:

GEN:

$$
[- \text { obl, }- \text { gov },+ \text { subj }]
$$$$
[- \text { obl, +gov, }- \text {-subj] }
$$$$
[-\mathrm{obl},+ \text { gov },+ \text { subj] }
$$

b. Inflection class

$\begin{array}{ll}\text { CLASS 1: } & {[+\mathrm{a},-\mathrm{b}]} \\ \text { CLASS 3: } & {[-\mathrm{a},-\mathrm{b}]} \\ \text { CLASS 2: } & {[-\mathrm{a},+\mathrm{b}]} \\ \text { CLASS 4: } & {[+\mathrm{a},+\mathrm{b}]}\end{array}$

Under these assumptions, the case exponents in (21) can be assumed to have the full specifications in (27); in addition, a zero exponent for the first inflection class, and a second marker /a/ for the second inflection class can be postulated for nominative contexts (I abstract away from the markers for the remaining two inflection classes here). These markers act as the leading forms that spread into the remaining environments for which no maximally faithful exponent is available in the input.

(27) Leading forms in Russian noun inflection:

$$
\begin{aligned}
& / \mathrm{u} / \leftrightarrow[-\mathrm{obl},+ \text { gov },- \text { subj, },-\mathrm{a},+\mathrm{b}] \\
& / \mathrm{y} / \leftrightarrow[-\mathrm{obl},+ \text { gov },+ \text { subj, },-\mathrm{a},+\mathrm{b}] \\
& / \mathrm{a} / 1 \leftrightarrow[-\mathrm{obl},+ \text { gov },+ \text { subj, },+\mathrm{a},-\mathrm{b}] \\
& / \varnothing / \leftrightarrow[- \text { obl, - gov, }+ \text { subj, },+\mathrm{a},-\mathrm{b}] \\
& / \mathrm{a} / 2 \leftrightarrow[-\mathrm{obl},- \text { gov },+ \text { subj, },-\mathrm{a},+\mathrm{b}]
\end{aligned}
$$

Focussing on classes 1 and 2, there is only one initial paradigm gap that needs to be filled by some unfaithful exponent: While there are fully specified forms for nominative, accusative, and genitive singular contexts with inflection class 2, there is no underlying exponent for accusative contexts with inflection class 1; see (28). 


\begin{tabular}{|c|c|c|}
\hline & {$[+\mathrm{a},-\mathrm{b}]$} & {$[-\mathrm{a},+\mathrm{b}]$} \\
\hline \hline$[-$ obl,--gov,+subj $]$ & $/ \varnothing /$ & $/ \mathrm{a} /$ \\
\hline$[-$ obl, +gov,--subj $]$ & & $/ \mathrm{u} /$ \\
\hline$[-$ obl, + gov, + subj $]$ & $/ \mathrm{a} /$ & $/ \mathrm{y} /$ \\
\hline
\end{tabular}

As before, the selection of the optimal exponent is determined by IDENT constraints for morpho-syntactic features. The input contains a stem with (fully specified) morphosyntactic features and the abstract item ExP; the latter includes all potential case exponents (all of which are fully specified) that noun stems can combine with in Russian. The undominated constraint MATCH ensures that the morpho-syntactic features of the stem and the exponent are identical; to achieve this, IDENT constraints may have to be minimally violated. Under Wunderlich's analysis of the animacy-based alternation in accusative contexts of class 1, the genitive/accusative syncretism with animates is basic, whereas the nominative/accusative syncretism with inanimates is brought about by a higher-ranked markedness constraint. This implies that spreading from nominative to accusative leads to a constraint profile that is worse than that of spreading from genitive to accusative. This follows from the fact that the nominative is two steps removed from the accusative ([-gov] and [+subj] must both be changed), whereas the genitive is only one step removed from the accusative (only $[+$ subj] needs to be changed). Since, therefore, the nominative candidate will be harmonically bounded by the genitive candidate in accusative environments (unless higher-ranked constraints intervene, see below), the ranking of IDENTGov and IDENTSubJ is not determined by the evidence discussed in this paper; still, for the sake of concreteness, I will adopt a ranking IDENTGOV 》 IDENTSUBJ in what follows. ${ }^{34}$ Essentially, these two faithfulness constraints take over the role of Wunderlich's MAx $[+h r]$, in the sense that they ensure that an accusative specification is closer to a genitive specification than to a nominative specification. I furthermore assume the ranking IDENTOBL $\gg$ IDENTSUBJ. ${ }^{35}$ For the time being, it can be assumed that the faithfulness constraints for inflection class information (IDENT-A, IDENT-B) are also ranked high; this precludes spreading from the (filled) accusative cell of class 2 into the accusative cell of class 1 .

Next, a markedness constraint that is analogous to Wunderlich's * $(+h r) / V$ inanim must be introduced into the system; cf. (29).

$$
\begin{aligned}
& * \text { Gov/InANim: } \\
& *[+ \text { gov }] /[-[- \text { obl, }- \text { subj,-anim }] \text { on a stem }
\end{aligned}
$$

This constraint blocks outputs with the feature [+gov] in inanimate accusative contexts. However, in contrast to what is the case with the other constraints discussed so far in this paper, it does not suffice to assume that ${ }^{*}$ Gov/INANIM applies only to the inflectional exponents: In that case, MATCH would have to be violated, which I have assumed to 
be impossible throughout. Thus, it must be assumed that ${ }^{*}$ Gov/InANIM is in fact a restriction on stems that can change the morpho-syntactic features there, in violation of stem faithfulness (I abbreviate the relevant constraints as IDENT-STEM). In other words: *Gov/InANIm effects a change of the context against which an exponent is matched, by turning a [+gov] specification into a [-gov] specification (I assume a complete deletion of the feature not to be a viable option here). This makes the similarity of Wunderlich's analysis to approaches that rely on impoverishment even more perspicuous. ${ }^{36}$

Finally, in Wunderlich's analysis, a more specific, high-ranked faithfulness constraint $\operatorname{MAx}(+h r) /-p l$, a] ensures that the accusative marker persists with inanimate items in class 2; an analogous constraint is $\operatorname{IdentGov}(C l 2, S g)$ in (30). Like *Gov/Inanim, this constraint must be assumed to apply to stems, not inflectional exponents (IDENT$\operatorname{Gov}(C l 2, S g)$ is a member of IDENTSTEM).

(30) $\operatorname{IdentGov}(C l 2, S g)$ :

$[ \pm$ gov $]$ of the input must not be changed in the output of a stem in the context $[-\mathrm{pl},-\mathrm{a},+\mathrm{b}]$.

With all the necessary assumptions in place, consider first the case of animate accusative contexts in inflection class 1 ; see tableau $\mathrm{T}_{13}$. Note that undominated MATCH is left out; the three high-ranked constraints applying to stems are graphically separated from constraints for exponents by double rules. ${ }^{37} \mathrm{O}_{1}-\mathrm{O}_{5}$ are candidates that do not change morpho-syntactic features of the stem. In contrast, in $\mathrm{O}_{6}-\mathrm{O}_{10}$, stem faithfulness is fatally violated by changing [+gov] of the input to [-gov] in the output on the stem; this does not lead to an improved behaviour with respect to any higher-ranked constraint. ${ }^{38}$

Tableau $T_{13}$ : Animate accusative contexts, class 1 stems

\begin{tabular}{|c|c|c|c|c|c|c|c|}
\hline Input: student $\leftrightarrow[-$ obl, + gov,- subj $,+\mathrm{a},-\mathrm{b},+$ anim $]$ & IDENTGOV & $* \mathrm{GOV}$ & IDENT & IDEN' $^{\prime}$ & IDENT & IDENT & IDENT \\
\hline ExP & $(C l 2 S g)$ & INANIM & STEM & $\mathrm{A}, \mathrm{B}$ & Gov & OBL & SuBJ \\
\hline $\mathrm{O}_{1}:$ stud.-u $\leftrightarrow[-\mathrm{obl},+$ gov,- subj, $,-a,+b]$ & & & & $* ! *$ & & & \\
\hline $\mathrm{O}_{2}:$ stud.-y $\leftrightarrow[-\mathrm{obl},+$ gov $,+s u b j,-a,+b]$ & & & & $* ! *$ & & & * \\
\hline 酸: stud.-a $\mathrm{a}_{1} \leftrightarrow[-\mathrm{obl},+\mathrm{gov},+s u b j,+\mathrm{a},-\mathrm{b}]$ & & & & & & & $*$ \\
\hline $\mathrm{O}_{4}:$ stud.- $\varnothing \leftrightarrow[-\mathrm{obl},-$ gov $,+s u b j,+\mathrm{a},-\mathrm{b}]$ & & & & & *! & & * \\
\hline $\mathrm{O}_{5}:$ stud.--a $2 \leftrightarrow[-$ obl, - gov $,+s u b j,-a,+b]$ & & & & $* ! *$ & $*$ & & $*$ \\
\hline $\mathrm{O}_{6}:$ stud. $_{\left[- \text {gov }^{-}-\mathrm{u} \leftrightarrow[-\mathrm{obl},+ \text { gov },-\mathrm{subj},-a,+b]\right.}$ & & & $* !$ & $* *$ & $*$ & & \\
\hline $\mathrm{O}_{7}:$ stud. ${ }_{[- \text {gov }]^{-y} \leftrightarrow\left[-\mathrm{obl},+ \text { gov },+ \text { subj }_{-}-a,+b\right]}$ & & & $* !$ & $* *$ & * & & * \\
\hline $\mathrm{O}_{8}:$ stud. $_{\left[- \text {gov }^{-} \mathrm{a}_{1} \leftrightarrow[-\mathrm{obl},+ \text { gov },+ \text { subj, }+\mathrm{a},-\mathrm{b}]\right.}$ & & & $* !$ & & $*$ & & $*$ \\
\hline $\mathrm{O}_{9}:$ stud. $_{[- \text {gov }]^{-} \varnothing \leftrightarrow[- \text { obl, },- \text { gov },+s u b j,+\mathrm{a},-\mathrm{b}]}$ & & & $* !$ & & & & $*$ \\
\hline $\mathrm{O}_{10}:$ stud. $[- \text { gov }]^{-\mathrm{a}_{2}} \leftrightarrow[-\mathrm{obl},-$ gov $,+s u b j,-a,+b]$ & & & $* !$ & $* *$ & & & * \\
\hline
\end{tabular}

In inanimate accusative contexts with class 1 stems, ${ }^{*}$ Gov/INANIM becomes relevant. The ranking * Gov/INANIM $\gg$ IDENTSTEM triggers a change from $[+$ gov $]$ to [-gov] on the stem. Consequently, output $\mathrm{O}_{9}$ becomes optimal: Spreading takes place from the 
nominative, and not from the genitive. This is shown in tableau $T_{14}$.

Tableau $T_{14}$ : Inanimate accusative contexts, class 1 stems

\begin{tabular}{|c|c|c|c|c|c|c|c|}
\hline $\begin{array}{l}\text { Input: stol } \leftrightarrow[- \text { obl, }+ \text { gov },- \text { subj, }+\mathrm{a},-\mathrm{b},- \text { anim }] \\
\text { ExP }\end{array}$ & \begin{tabular}{|c} 
IDENTGOV \\
$(\mathrm{Cl} 2 \mathrm{Sg})$
\end{tabular} & $\begin{array}{l}* \text { GOV } \\
\text { INANIM }\end{array}$ & \begin{tabular}{|l|l|l|l} 
IDENT \\
STEM \\
\end{tabular} & \begin{tabular}{|c} 
IDENT \\
$\mathrm{A}, \mathrm{B}$
\end{tabular} & $\begin{array}{c}\text { IDENT } \\
\text { Gov }\end{array}$ & $\begin{array}{c}\text { IDENT } \\
\text { OBL }\end{array}$ & \begin{tabular}{|c|} 
IDENT \\
SuBJ \\
\end{tabular} \\
\hline 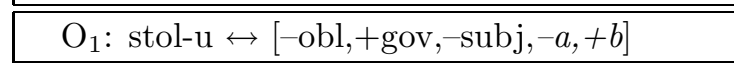 & & 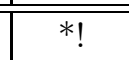 & & ** & & & \\
\hline $\mathrm{O}_{2}:$ stol-y $\leftrightarrow[-\mathrm{obl},+$ gov $,+s u b j,-a,+b]$ & & $* !$ & & ** & & & $*$ \\
\hline $\mathrm{O}_{3}:$ stol- $\mathrm{a}_{1} \leftrightarrow[-\mathrm{obl},+$ gov $,+s u b j,+\mathrm{a},-\mathrm{b}]$ & & $* !$ & & & & & * \\
\hline $\mathrm{O}_{4}:$ stol- $\varnothing \leftrightarrow[-\mathrm{obl},-$ gov,+ subj, $+\mathrm{a},-\mathrm{b}]$ & & $* !$ & & & * & & * \\
\hline $\mathrm{O}_{5}:$ stol- $\mathrm{a}_{2} \leftrightarrow[-\mathrm{obl},-$ gov $,+s u b j,-a,+b]$ & & $* !$ & & ** & $*$ & & $*$ \\
\hline$\overline{\mathrm{O}}_{6}:$ stol $\left._{[- \text {gov }}\right]^{-\mathrm{u}} \leftrightarrow\left[-\mathrm{obl},+\right.$ gov $\left.,-\mathrm{subj}_{,}-a,+b\right]$ & & & * & *!* & $*$ & & \\
\hline $\mathrm{O}_{7}:$ stol $_{[- \text {gov }]}-\mathrm{y} \leftrightarrow[-\mathrm{obl},+$ gov $,+s u b j,-a,+b]$ & & & $*$ & $* ! *$ & $*$ & & $*$ \\
\hline $\left.\mathrm{O}_{8}: \operatorname{stol}_{[-\mathrm{gov}]}\right]^{-\mathrm{a}_{1}} \leftrightarrow[-\mathrm{obl},+$ gov $,+\operatorname{subj},+\mathrm{a},-\mathrm{b}]$ & & & * & & $* !$ & & $*$ \\
\hline $\mathrm{O}_{9}: \operatorname{stol}_{[-\mathrm{gov}]} \varnothing \leftrightarrow[-\mathrm{obl},-$ gov $,+s u b j,+\mathrm{a},-\mathrm{b}]$ & & & $*$ & & & & $*$ \\
\hline $\mathrm{O}_{10}: \operatorname{stol}_{[-\mathrm{gov}]}-\mathrm{a}_{2} \leftrightarrow[-\mathrm{obl},-$ gov $,+s u b j,-a,+b]$ & & & * & $* ! *$ & & & * \\
\hline
\end{tabular}

Turning to accusative singular contexts of the second declension, a high-ranked IDENT$\operatorname{Gov}(C l 2, S g)$ makes sure that there can be no modification of morpho-syntactic features of the stem in inanimate contexts, and therefore no spreading of the nominative marker /a/ (as in output $\mathrm{O}_{10}$ ) into the accusative cell; see tableau $\mathrm{T}_{15} \cdot{ }^{39}$

Tableau $T_{15}$ : Inanimate accusative contexts, class 2 stems

\begin{tabular}{|c|c|c|c|c|c|c|c|}
\hline $\begin{array}{l}\text { Input: kart } \leftrightarrow[- \text { obl, }+ \text { gov },- \text { subj },-a,+b,- \text { anim }], \\
\text { ExP }\end{array}$ & \begin{tabular}{|c} 
IDENTGOV \\
$(C l 2 S g)$ \\
\end{tabular} & $\begin{array}{l}* \text { GOV } \\
\text { INANIM } \\
\end{array}$ & \begin{tabular}{|c|} 
IDENT \\
STEM \\
\end{tabular} & $\begin{array}{c}\text { IDEN? } \\
\text { A,B }\end{array}$ & $\begin{array}{r}\text { IDEN" } \\
\text { Gov }\end{array}$ & $\begin{array}{c}\text { IDENT } \\
\text { OBL } \\
\end{array}$ & \begin{tabular}{|c|} 
IDENT \\
SuBJ \\
\end{tabular} \\
\hline $\mathrm{O}_{1}:$ kart-u $\leftrightarrow[-\mathrm{obl},+$ gov,,- subj, $,-\mathrm{a},+\mathrm{b}]$ & & * & & & & & \\
\hline $\mathrm{O}_{2}:$ kart-y $\leftrightarrow[-\mathrm{obl},+$ gov $,+s u b j,-\mathrm{a},+\mathrm{b}]$ & & * & & & & & $* !$ \\
\hline $\mathrm{O}_{3}:$ kart-a $1 \leftrightarrow[-$ obl, + gov $,+s u b j,+a,-b]$ & & $*$ & & $* ! *$ & & & $*$ \\
\hline $\mathrm{O}_{4}:$ kart- $\varnothing \leftrightarrow[-\mathrm{obl},-$ gov $,+s u b j,+a,-b]$ & & * & & $* !^{*}$ & * & & $*$ \\
\hline $\mathrm{O}_{5}:$ kart-a $\mathrm{a}_{2} \leftrightarrow[-\mathrm{obl},-$ gov $,+s u b j,-\mathrm{a},+\mathrm{b}]$ & & * & & & $* !$ & & $*$ \\
\hline 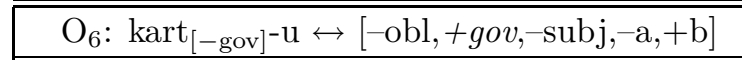 & $* !$ & & & & ** & & \\
\hline $\mathrm{O}_{7}:$ kart $_{[- \text {gov }]}-\mathrm{y} \leftrightarrow[-\mathrm{obl},+$ gov,+ subj $,-\mathrm{a},+\mathrm{b}]$ & $* !$ & & & & * & & $*$ \\
\hline $\mathrm{O}_{8}: \operatorname{kart}_{[- \text {gov }]}-\mathrm{a}_{1} \leftrightarrow[-\mathrm{obl},+$ gov $,+\operatorname{subj},+a,-b]$ & $* !$ & & & $* *$ & * & & * \\
\hline $\mathrm{O}_{9}: \operatorname{kart}_{[-\mathrm{gov}]}-\varnothing \leftrightarrow[-\mathrm{obl},-$ gov $,+s u b j,+a,-b]$ & $* !$ & & & ** & & & $*$ \\
\hline $\mathrm{O}_{10}: \operatorname{kart}_{[- \text {gov }]} \mathrm{a}_{2} \leftrightarrow[-\mathrm{obl},-$ gov $,+s u b j,-\mathrm{a},+\mathrm{b}]$ & $* !$ & & & & & & $*$ \\
\hline
\end{tabular}

Along these lines, the gist of Wunderlich's (2004) approach can be transferred into an underspecification-free analysis. The system can easily be extended to the remaining inflection classes, and to the animacy-based alternation in the plural (which is derived by Wunderlich in a similar way). 


\section{General Discussion}

\subsection{Morphology without Underspecification}

So far, I have shown that the non-optimality theoretic underspecification-based analysis of German determiner inflection developed in Wiese (1999) and the optimality-theoretic underspecification-based analyses of Italian object clitics in Grimshaw (2001), and of Russian noun inflection in Wunderlich (2004), can all be reconstructed in an optimalitytheoretic approach that does not rely on underspecification; rather, it is based on an unfaithful spreading of certain exponents ('leading forms') to paradigm cells for which no matching exponent exists in the inventory. ${ }^{40}$ Given that the concept of underspecification may not be unproblematic in optimality theory, this is a welcome result.

It can also be noted that underspecification-based approaches to syncretism (within optimality theory as well as outside of optimality theory) give rise to certain conceptual problems in and of themselves, problems that so far do not seem to have been addressed satisfactorily. For instance, the deep morphology/syntax asymmetry that necessarily arises as a result of morphological underspecification is an open problem: It is a priori unclear why syntactic operations (e.g., agreement rules, or subcategorization/selection) can never access underspecified morpho-syntactic information. For instance, verbs in German do not subcategorize for (or govern) NPs with an underspecified case information [+obl]; they rather have to subcategorize for NPs that are either $[+$ obl, +gov] (dative) or $[+$ obl,--gov] (genitive). Similarly, agreement rules (like those within NPs in German, or between argument NP and V in other languages, like Russian) do not involve underspecified gender information (like $[+$ masc $]$ ); syntactic agreement is with respect to fully specified gender information only $([+$ masc,- fem $]$ (masculine gender) or $[+$ masc,+ fem $]$ (neuter gender) in German). If there is no morphological underspecification to begin with, the problem of accounting for what is otherwise a curious asymmetry between morphology and syntax disappears. Nevertheless, there is still an asymmetry that remains, and that looks irreducible: Given that there is no morphological underspecification, it is clear why a single feature [+obl] is not a piece of information that syntax can deal with (assuming that the fine structure of categories is generally inaccessible), but it is not clear, from a purely syntactic perspective, why there should be a decomposition of categories like [dative] as $[+$ obl, +gov] in the first place; this fine structure is purely motivated by morphological requirements. ${ }^{41}$

\subsection{Restrictiveness and Empirical Coverage}

Independently of these conceptual considerations, there are empirical differences between an underspecification-free approach and underspecification-based approaches. For one thing, the underspecification-free aproach is somewhat more limited (at least in the form presupposed so far), in that it can derive fewer instances of syncretism than an underspecification-based approach, at least as a tendency. To see this, it suffices to 
briefly consider the underspecification-based approaches to German determiner inflection developed by Bierwisch (1967), Blevins (1995), and Wunderlich (1997a), all of which make do with eight basic exponents (rather than nine, as in Wiese (1999) and the present approach developed in section 2.2). ${ }^{42}$ There does not seem to be an obvious way to derive the paradigm of German determiner inflection by postulating fewer leading forms, at least not without enriching the basic inventory of (decomposed) morpho-syntactic features (and adding appropriate faithfulness constraints that refer to these features). This limitation is partly due to the fact that, in contrast to what is the case with underspecificationbased approaches, there is no room for radically underspecified elsewhere markers in underspecification-free analyses, i.e., exponents that are compatible with any morphosyntactic specification, and that can therefore show up in any paradigm cell (but are typically blocked by more specific markers). The postulation of elsewhere markers can account for a highly discontinuous distribution of an exponent in a uniform way. However, the present approach allows only a sufficiently "similar" marker to spread to a paradigm cell with a different morpho-syntactic specification (the notion of minimality, implemented as the Nearest Neighbour Principle in Weisser (2007, 26), and as the Minimality principle in Lahne $(2007,11))$; there is no such thing as a "universal spreader".

On the other hand, limitations of the present analysis can also partly be traced back to the avoidance of potential ranking dilemmas. As noted in section 1, in an underspecification-based approach like Wiese's (1999), it is in principle possible to conflate the two oblique $/ \mathrm{r} /$ 's $\left(/ \mathrm{r} /{ }^{6}\right.$ and $\left./ \mathrm{r} /{ }^{8}\right)$ by dispensing with $/ \mathrm{r} /{ }^{6}$, maintaining $/ \mathrm{r} /{ }^{8}$ in the form that it has in (5) (viz., specified as [+obl]), and narrowing down $/ \mathrm{n} /{ }^{7}$ 's specification from $[+\mathrm{obl},+$ gov $]$ (as in $(5)$ ) to $[+\mathrm{obl},+$ gov,- fem $]$, so as to remove $/ \mathrm{n} /{ }^{7}$ from feminine singular dative cells (where it would block $/ \mathrm{r} /{ }^{8}$; see $\left.(7)\right) .{ }^{43}$

In the present approach, ceteris paribus, none of the two $/ \mathrm{r} /$ exponents (i.e., $/ \mathrm{r} / 8$ and $/ \mathrm{r} / 9$ in the list of leading forms in (10)) can be dispensed with in favour of the remaining one. To see this, suppose that $/ \mathrm{r} / 9$ were in fact not present as a leading form in ExP. The relevant part (i.e., the $[+\mathrm{obl},-$-masc] domain) of the incomplete paradigm with leading forms only would then look as in (31) (compare (14)).

(31) Incomplete paradigm of German determiner inflection: a wrong prediction

\begin{tabular}{|l|c|c|}
\hline $\begin{array}{l}\text { dies } \\
\text { 'this' }\end{array}$ & $\begin{array}{l}\text { FEMININE.SG } \\
{[- \text { masc, }+ \text { fem }]}\end{array}$ & $\begin{array}{c}\text { PLURAL } \\
{[- \text { masc },-f e m]}\end{array}$ \\
\hline \hline$[+$ gov,+ obl $]$ & & $/ \mathrm{h} / 7$ \\
\hline$[-$ gov,+ obl $]$ & $/ \mathrm{r} / 8$ & \\
\hline
\end{tabular}

To derive the full paradigm, it would have to be ensured that $/ \mathrm{r} / 8$ spreads to both empty cells - not just to the dative feminine cell (as in the analysis developed above), but also to the genitive plural cell. Of course, $/ \mathrm{r} / 8$ can only spread to genitive plural contexts if spreading of $/ \mathrm{n} / 7$ yields a constraint profile that is worse. As it stands, this is not the 
case; see tableau $\mathrm{T}_{16} \cdot{ }^{44}$

Tableau $T_{16}$ : A wrong prediction for Gen.Pl. contexts if $/ r / 9$ is not present

\begin{tabular}{|l||c|c|c|c|}
\hline Input: dies $\leftrightarrow[-$ masc,- fem,- gov,+ obl $]$, & IDENT & IDENT & IDENT & IDENT \\
ExP & MASC & OBL & FEM & Gov \\
\hline \hline$-\mathrm{O}_{7}:$ dies- $\mathrm{n}_{7} \leftrightarrow[-$ masc,- fem,+ gov,+ obl $]$ & & & & $*$ \\
\hline $\mathrm{O}_{8}:$ dies- $\mathrm{r}_{8} \leftrightarrow[-$ masc,+ fem,- gov,$+\mathrm{obl}]$ & & & $* !$ & \\
\hline
\end{tabular}

To make $/ \mathrm{r} / 8$ win the competition in genitive plural contexts in the absence of $/ \mathrm{r} / 9$, a ranking of IDENTGOV (which is violated by spreading of $/ \mathrm{n} / 7$ ) over IDENTFEM (which is violated by spreading of $/ \mathrm{r} / 8$ ) would be called for; but then, spreading of $/ \mathrm{r} / 8$ to dative feminine cells should be blocked (because $/ \mathrm{n} / 7$ would become optimal in this context, with the gender/number barrier now easier to cross than the case barrier in the oblique domain). This is shown in tableau $\mathrm{T}_{17}$ (compare $\mathrm{T}_{3}$ ).

Tableau $T_{17}$ : A wrong prediction for Dat.Fem.Sg. contexts under reranking

\begin{tabular}{|l||c|c|c|c|}
\hline Input: dies $\leftrightarrow[-$ masc,+ fem,+ gov,+ obl $]$, & IDENT & IDENT & IDENT & IDENT \\
Exp & MASC & OBL & Gov & FEM \\
\hline \hline O $_{7}:$ dies- $_{7} \leftrightarrow[-$ masc $,-f e m,+$ gov,+ obl $]$ & & & & $*$ \\
\hline $\mathrm{O}_{8}:$ dies- $_{8} \leftrightarrow[-$ masc,+ fem,- gov,+ obl $]$ & & & $* !$ & \\
\hline
\end{tabular}

Similarly, a ranking IDENTGOV $\gg$ IDENTFEM would wrongly predict $/ \mathrm{r} / 1$ (rather than $/ \mathrm{s} / 5$ ) to be optimal in nominative neuter singular contexts.

Ranking dilemmas of this type can in principle be avoided by adding more complex constraints on exponents. An obvious possibility would be to invoke the concept of contextual faithfulness (see Beckmann (1998) on positional faithfulness in phonology and Woolford (2007) for a recent application of contextually restricted faithfulness constraints in syntax): ${ }^{45}$ Assuming that faithfulness constraints can be contextually restricted, spreading of $/ \mathrm{n} / 7$ can successfully be blocked in genitive plural contexts without making wrong predictions for other domains of the paradigm of determiner inflection in German. ${ }^{46}$ Thus, suppose that, next to the original, pure IDENTGOV, there is another, contextually restricted constraint IDENTGOV $([-\mathrm{FEM}])$ that demands the preservation of $[+$ gov $] /[-$ gov $]$ in the context of $[-\mathrm{fem}]$. If IDEnTGov $([-\mathrm{FEM}])$ (minimally) outranks IdentFem, /r/9 can be dispensed with (given the original ranking IDENTFEM $\gg$ IDENTGOV). This is shown in tableau $\mathrm{T}_{18}$.

It can easily be verified that adding this new constraint would not make any wrong predictions for other domains: The only other [-fem] environments that are relevant are the non-oblique domain of the plural (where spreading of /e/6 will take place here as before - a violation of IDENTGOV $([-\mathrm{FEM}])$ is unproblematic, given that IDENTOBL and 
Tableau $T_{18}$ : Correct prediction for Gen.Pl. contexts without $/ r / 9$ : contextual faithfulness

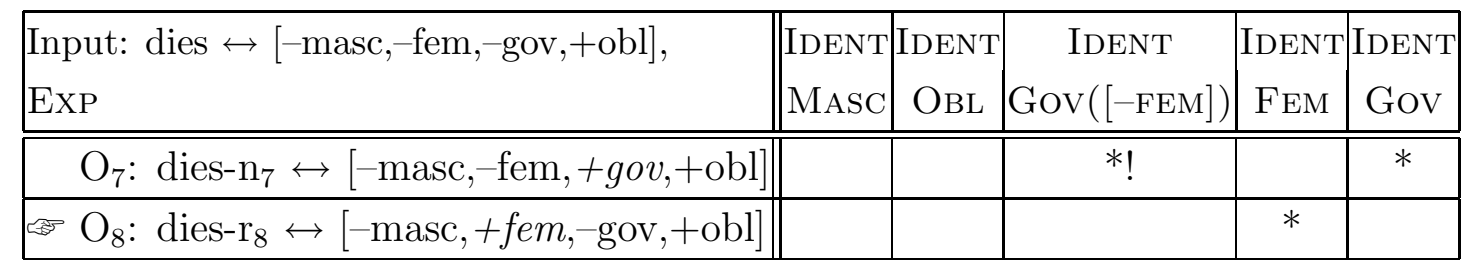

IDENTMASC are still higher ranked; compare, e.g., $\mathrm{T}_{2}$ ), and the domain of masculine singular (where no spreading occurs because all paradigm cells are filled by leading forms to begin with).

More generally, it can be noted that the present approach, in its simplest form (i.e., without tools like contextually restricted faithfulness constraints), cannot derive elsewhere patterns like the three-out-of-four distributions of exponents in (32) by assuming only two basic exponents: If $\mathrm{x}$ and $\mathrm{y}$ are leading forms, and $\mathrm{x}$ spreads to one cell, $\mathrm{y}$ will invariably spread to the other one because $\mathrm{x}$ spreading is then harmonically bounded by y spreading (independently of the question which cells $\mathrm{x}$ and $\mathrm{y}$ occupy as a result of their input specification). By adopting contextual faithfulness (or some other extension, see footnote 46), massive spreading of $\mathrm{x}$ can be effected, via blocking of y spreading.

Leading forms
\begin{tabular}{|c|c|}
\hline $\mathrm{x}$ & \\
\hline & $\mathrm{y}$ \\
\hline
\end{tabular}

Intended spreading

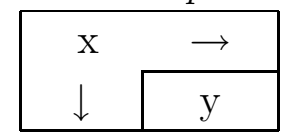

In line with this, patterns of homonymy like those found with verb inflection in English pose an obvious challenge. Consider the paradigm for the verb be in (33).

The English verb 'be'
\begin{tabular}{l|ll} 
& Singular & Plural \\
\hline 1 & am & are \\
2 & are & are \\
3 & is & are
\end{tabular}

(33) is standardly accounted for by assuming are to be an elsewhere exponent (see Williams (1994), among others). In an underspefication-based approach, this can be implemented by postulating the rules in (34). Here, /am/ and /is/ block the elsewhere marker /are/ in 1. and 3. person singular contexts because they are more specific; in all other contexts, maximally nonspecific /are/ is the only possible form. ${ }^{47}$

(34) Underspecification approach:
a. $/ \mathrm{am} / \leftrightarrow[-2,-\mathrm{pl}]$
b. $/$ is $/ \leftrightarrow[-1,-2,-\mathrm{pl}]$
c. $/$ are $/ \leftrightarrow[\quad]$

In the present approach, a single leading form / are/ cannot be maintained unless (some- 
thing like) contextual faithfulness is adopted: To permit spreading of /are/ throughout the plural, faithfulness constraints for number must outrank all faithfulness constraints for person; but then, /are/ cannot spread to 2. person singular contexts even if we assume that /are/ is inherently specified as 2. person (plural). Thus, without contextual faithfulness, the present approach would seem to suggest the presence of two leadings forms /are/ - one for 2. person singular, and one for the plural. ${ }^{48}$ Similar issues arise with regular verb inflection in English, where a standard underspecification-based analysis would postulate a specific form /s/ for 3. person singular contexts, and a zero marker elsewhere.

For the time being, I will leave open the question of whether extending what looks like the simplest system by (means like) contextual faithfulness to cover additional cases of syncretism is the right way to proceed. However, one might argue that the restrictiveness embodied in the original, pure approach is not necessarily a bad thing, and that this might speak against adopting additional tools like contextual faithfulness; at least for the empirical domain of German determiner inflection, this conclusion might be reinforced by the fact that none of the existing underspecification-based approaches to German determiner inflection is able to derive all instances of syncretism anyway (the step would be from postulating 9 leading forms to postulating 8 leading forms, in view of a minimal number of 5 distinct leading forms: one $/ \mathrm{e} /$, one $/ \mathrm{r} /$, one $/ \mathrm{n} /$, one $/ \mathrm{s} /$, and one $/ \mathrm{m} /$ ), and by the observation that the dividing line between the homonymies that can be derived systematically and the homonymies that cannot be derived is defined by whether or not marker identity breaks down when the whole NP domain is taken into account (cf. the discussion of (8) above).

Furthermore, it is worth pointing out that the systematic differentiation between purely underspecification-based types of syncretism (that can straightforwardly be covered by the leading-form approach developed in this paper) and underspecification-based types of syncretism that involve elswhere distributions is mirrored in the approach to morphological learning developed in Pertsova (2007). Against the background of an underspecification-based approach, Pertsova devises three learning algorithms for inflectional systems that differ with respect to the complexity of the systems that need to be acquired: The No-Homonymy Learner is the most restricted algorithm. It can only acquire systems where all instances of syncretism can be derived by reference to natural classes, without reference to elsewhere or default exponents; Pertsova calls an exponent a "homophone" or "homonym" in the technical sense if "its distribution cannot be described in terms of a single necessary and sufficient set of semantic values" (Pertsova $(2007,8)$ ). A second, much less restrictive Elsewhere Learner is an algorithm that can also acquire patterns that involve elsewhere exponents, and require a principled resolution of marker competitions, like the three-out-of-four distribution in (32). Finally, the least restrictive acquisition algorithm envisaged by Pertsova is the General Homonymy Learner, which can also learn overlapping patterns of marker identity, by postulating different entries. The kinds of syncretism that the underspecification-free optimality-theoretic approach devel- 
oped here can derive in the original, simple form (i.e., without contextual faithfulness) can all be learned by the No-Homonymy Learner in an underspecification-based approach, and would not require the additional complications induced by the Elsewhere Learner in such an approach. ${ }^{49}$ This would seem to directly confirm the claim that considerations relating to restrictiveness argue in favour of the pure underspecification-free approach, without recourse to contextual faithfulness (even if the actual learning algorithm devised by Pertsova is not available in such an approach; see the next subsection). ${ }^{50}$

\subsection{Storage and Acquisition}

The present, underspecification-free analysis differs from standard underspecificationbased approaches (again, be they optimality-theoretic or not) in its consequences for the mental storage of inflectional systems. In underspecification-based approaches, all different occurrences of an exponent have the same status because the exponent does not treat any of the contexts in which it can occur differently from any other one. In contrast, in the underspecification-free analysis advanced here, there is a clear primacy of certain contexts of occurrence over others. For instance, under the present analysis of German determiner inflection, $/ \mathrm{m} / 3$ is underlyingly a masculine dative marker, which is then also used in neuter dative contexts; $/ \mathrm{s} / 5$ is first and foremost an accusative neuter marker which is then also used in nominative neuter contexts; and so forth. To some extent, the decisions on which occurrence of an exponent's distribution is to count as primary (i.e., qualify as the leading form), and which occurrences of the distribution are secondary (involving a violation of faithfulness) have been arbitrary in sections 2 and 3, at least from a purely synchronic, grammar-internal point of view. However, given this approach, one would expect there to be evidence for occurrence asymmetries of inflectional exponents in other domains (i.e., outside grammatical theory) which can be addressed by research in areas like diachronic linguistics, corpus linguistics, and psycholinguistics. Indeed, it does not strike me as unreasonable to assume that occurrence asymmetries can be detected with markers when diachronic evidence is taken into account (see, e.g., Baerman, Brown \& Corbett (2005) on neuter exponents in Indo-European). Similarly, evidence from language acquisition and frequency distributions based on corpus data may well support an asymmetry of marker occurrences as it is predicted by the underspecification-free approach based on leading forms.

In general, it should be possible to come up with experimental psycholinguistic evidence for or against underspecification; however, it seems that so far, no convincing evidence for or against underspecified morpho-syntactic specifications of inflectional exponents has been provided on the basis of psycholinguistic experiments. ${ }^{51}$ It is likely, though, that future studies in this area (both behavioural studies and ERP studies) will have some bearing on this issue, and might eventually help to decide between the models. However, these questions go beyond the scope of the present paper.

Let me end this paper with a few speculations on how inflectional systems with syn- 
cretism that are derived by spreading of leading forms (rather than by underspecification) can be acquired. For underspecification-based systems, it can be assumed that children look for properties that the various environments in which exponents with the same form occur have in common; i.e., they learn underspecified feature structures of exponents by intersecting the sets of the different (fully specified) environments; see Harley (2001) and Pertsova (2007) for proposals along these lines (essentially, this is what Pertsova's NoHomonymy learner mentioned above does). On this view, the child assumes a syncretism to be systematic (i.e., going back to a single entry) whenever possible (see Pertsova (2007, 135)), and postulates two separate entries only as a last resort (e.g., when the interaction of (i) the Subset Principle and (ii) a system of decomposed features that is assumed as given fail to permit a coherent underspecified feature structure underlying two occurrences of one exponent form); this is essentially the meta-grammatical Avoid Accidental Homonymy condition assumed in Embick (2003), or the Syncretism Principle argued for in Müller (2007a) and Alexiadou \& Müller (2008). Evidently, such an approach is not available in an underspecification-free approach such as the one developed here: Intersection invariably leads to underspecification. In what follows, I briefly sketch a possible alternative.

Given the Syncretism Principle, the child assumes a syncretism to be systematic whenever possible (given restrictions on what can act as a decomposed morpho-syntactic feature, and given a set of faithfulness constraints that refer to these features). Suppose now that it is a characteristic property of leading forms that they "come first", i.e., they are highly prominent in the child's input (at least more so than the forms that the analysis classifies as gaps in the input), e.g., because they are more frequent. The child then fixes its input ExP by integrating a recognized leading form. Upon discovering identical output forms with a different syntactic distribution, it attempts to derive the form from one of the existing members of ExP, by demoting the relevant faithfulness constraints (see Tesar \& Smolensky (2000)). If successful (and compatible with the data that the child's earlier grammar can generate), the new grammar is adopted; otherwise, a new exponent with a new feature specification (that of the syntactic context in which that form was encountered) is postulated. - Needless to say, such a model would ultimately have to be worked out in much more detail. Questions arise with respect to the acquisition of impoverishment-like mechanisms resulting from optimal faithfulness violations with stems, as discussed in subsection 3.2.2 above (although these questions arise in exactly the same way in standard impoverishment-based approaches, and in Wunderlich's original account). It should also be emphasized that other acquisition scenarios are conceivable as well. ${ }^{52}$ For the time being, I will leave it at that.

\section{Notes}

\footnotetext{
${ }^{1}$ System-wide patterns of syncretism have also been accounted for via (post-syntactic) underspecification of syntactic insertion contexts (rather than of morphological exponents) in Distributed Morphology,
} 
by means of impoverishment rules (see Bonet (1991), Noyer (1992, 1998), Halle \& Marantz (1993, 1994), Bobaljik (2002), and Frampton (2002)).

${ }^{2}$ In fact, there may be twenty-four paradigm cells if one assumes separate gender specifications for plural contexts; however, gender is never distinguished in the plural in German, so it is unclear whether the two additional columns need to be assumed.

${ }^{3}$ Strictly speaking, underspecification does not have to go hand in hand with feature decomposition (see, e.g., Baerman et al. (2005) and Pertsova (2007)); however, an underspecification approach that does without feature decomposition is necessarily much less powerful, and can accordingly derive much fewer instances of syncretism. All the theories of inflectional morphology mentioned above can be shown to employ more abstract, decomposed morpho-syntactic features (often also including decomposed inflection class features; see Müller (2007a)), even in cases where there are explicit claims to the contrary (see Müller (2008)).

${ }^{4}$ See Halle (1997). Versions of the constraint are known as the Specificity Condition, the Elsewhere Principle, the Blocking Principle, Panini's Principle, or the Proper Inclusion Principle. See Kiparsky (1973), Di Sciullo \& Williams (1987), Fanselow (1991), Anderson (1992), Lumsden (1992), Noyer (1992), Williams (1994), Williams (1997), Wiese (1999), and Stump (2001).

${ }^{5} \mathrm{~A}$ concept of specificity based on a hierarchy of feature classes is argued for in Lumsden (1992), Noyer (1992), Wiese (1999), and Müller (2005). Alternative versions of specificity rely exclusively on the number of features that are associated with a given exponent.

${ }^{6}$ The superscripts have no theoretical status; their only purpose is to unambiguously identify markers in the remaining cases of unresolved marker homonymy. Also note that the markers (except for $/ \mathrm{e} /{ }^{9}$ ) have their vocalic part ( $\partial$, written as 'e') stripped off; the assumption here is that Schwa insertion in front of a consonantal exponent is a regular phonological operation that does not have to be taken care of in the morphology. Finally, let me reiterate that nothing in (5) (or, for that matter, (4)) is incompatible with any of the morphological theories mentioned above; in particular, the exponence entries in (5) could just as well be formulated as rules of exponence in A-Morphous Morphology, Paradigm Function Morphology, or Network Morphology.

${ }^{7}$ One may well ask oneself what the alternative to feature decomposition could be vis-à-vis the paradigm of German determiner inflection. For instance, one possibility would be not to postulate a single entry for $/ \mathrm{m} /$ (because this presupposes an abstract feature that captures masculine and neuter as a natural class); however, it seems unlikely that one could maintain the assumption that we are dealing with two genuinely separate markers here. Similarly, one might assume that there is no single entry for the $/ \mathrm{s} /$ with neuters in nominative and the $/ \mathrm{s} /$ with neuters in accusative contexts (since this requires an abstract feature that captures nominative and accusative as a natural class); but again, it seems clearly inadequate to stipulate two separate /s/ exponents here, and I am not aware of any approach employing underspecification that proceeds in this way. Note that there is no way to construe the required features here as non-abstract (i.e., directly motivated outside the distribution of morphological exponents); there simply is no grammatical category like (e.g.) "non-feminine" or "non-oblique" in the syntax of German. So, everyone who looks at paradigms like (1) from a perspective that admits accounting for syncretism by underspecification must be prepared to adopt decomposition to some extent. Accordingly, decomposition of syntactically motivated grammatical categories into more abstract features can be found in many theories; cf., e.g., Stump (2001) and Baerman et al. (2005). The only question then is where to stop; but Wiese actually does not do much more than use the decomposition required for the two (fairly uncontroversial) cases just mentioned, and put the resulting system to use.

${ }^{8}$ Note in passing that there are other properties of Wiese's analyses that, in my view at least, make it superior to competing accounts of syncretism in determiner inflection in German. Most notably, there are intriguing predictions about iconicity of (underspecified) exponents - the more underspecified an exponent is, the less marked (or less heavy) it is phonologically. Incidentally, such considerations provide a third 
reason against making $/ \mathrm{n} /{ }^{7}$ more specific in order to reduce the number of entries for $/ \mathrm{r} /$ : This would be incompatible with Wiese's assumptions about iconicity, according to which $/ \mathrm{m} /$ and $/ \mathrm{s} /$ should be the most specific exponents, $/ \mathrm{n} /$ and $/ \mathrm{r} /$ should have an intermediate status with respect to specificity, and /e/ should be least specific. Another virtue of this analysis concerns the identification of the elsewhere marker (which, e.g., Bierwisch and Wunderlich arguably got wrong, since they identify /s/ rather than /e/ als the elsewhere exponent). However, these properties of Wiese's account are not directly related to the goals I pursue in this article. (As a matter of fact, the proposal to be developed below will not offer an obvious, simple way to accomodate Wiese's concept of iconicity since that concept crucially relies on underspecification).

${ }^{9}$ Other approaches to syncretism in optimality theory include the Optimal Paradigms model of McCarthy (2005), which however does not say much about syncretism as such, except for cases where the syncretism (perhaps a partial, or block, syncretism affecting only part of an inflected word) is purely phonologically conditioned; the analyses in Müller (2002, 2007b) and Carstairs-McCarthy (2008), which dispense entirely with a correlation of an exponent's form with its function (i.e., specification) and thus qualify as radically a-morphematic; and the approach in Xu (2007), which can essentially be viewed as an optimality-theoretic implementation of the concept of a "rule of referral" (see Zwicky (1985), Stump (2001), and Baerman, Brown \& Corbett (2005), among others), where a rule of referral states that the exponent for a particular fully specified morpho-syntactic feature context (i.e., paradigm cell) is used as the exponent for another context (overriding whatever the rules of exponence may otherwise predict). For reasons of space, I will not consider these approaches in what follows; suffice it to note that none of them permits a straightforward implementation of the hypothesis that exponents can be syncretic if they are sufficiently similar in their morpho-syntactic feature specifications, which I will presuppose throughout this article. - That said, the approach that I will develop in the next section can be viewed as an attempt to provide a principled concept of referral in optimality theory.

${ }^{10}$ However, since these interfering markedness constraints may force deletion, addition, or modification of input material (corresponding to optimal violations of MAX, DEP, and IDENT constraints), the resulting system is in principle more powerful than an impoverishment-based Distributed Morphology system, which can only effect deletion; but see footnote 36 below.

${ }^{11}$ As noted by a reviewer, it is in fact not clear whether these arguments against underspecification based on phonology can be extended to morphology. For instance, optimality-theoretic underspecification-based approaches to syncretism typically involve underspecification of outputs rather than inputs. Still, the assumption that underspecification is a dubious concept from an optimality-theoretic perspective strikes me as valid independently of more technical arguments: As I will show, standard optimality-theoretic procedures are powerful enough to account for syncretism; and given that syncretism thus can be derived without underspecification, there is then every reason to pursue the idea that it also must be derived without recourse to this concept, by Occam's razor.

${ }^{12}$ In particular, in studies like Wurzel (1984) and Blevins (2004), leading forms ('Kennformen') are used as predictors for inflectional patterns, i.e., they provide inflection class information. This is not the case in the present study (or, for that matter, in Baerman's (2009) analysis of inflectional patterns in Nuer in terms of principle parts).

${ }^{13}$ Thus, the approach to be developed here in effect treats syncretism as a special case of (generalized) deponency, at least under the assumption that deponency involves a mismatch between an inflectional exponent and the morpho-syntactic feature specification it is used for in syntax, and not a mismatch between syntax and semantics ('form-deponency' vs. 'property-deponency', in Stump's (2007) terms). As shown by Corbett $(2007,35)$, there are both similarities and principled differences between syncretism and deponency. As for the differences, deponency not not retain the original function, it often creates defective paradigms, and it typically affects 'slabs' rather than individual paradigm cells, all in contrast to syncretism. An extension of the present model approach to syncretism to the area of deponency does 
not seem to be out of reach. However, it may not be entirely straightforward either (e.g., it can be derived easily that a certain verb form of a Latin deponent verb with passive morphology may be used in active contexts, assuming that there is an initial gap here; but it is then still far from clear why the same form cannot be used anymore in passive contexts, where it would seem to fit perfectly); in any case, such an extension is beyond the scope of the present article.

${ }^{14}$ In general, in cases where there is more than one affix position for a stem, there will be a sequence of ExPs, corresponding to different functional morphemes in Distributed Morphology and to different rule blocks in A-Morphous Morphology and Paradigm Function Morphology.

${ }^{15}$ ExP is comparable to the abstract element RED in McCarthy \& Prince's (1994) theory of reduplication. Similarly, it is common practice in optimality to approach phonologically conditioned allomorphy in essentially this way, by postulating a set of allomorphs in the input from which one allomorph is selected in each output (without thereby giving rise to a faithfulness violation); see Kager (1996), Mascaró (1996), Itô \& Mester (2004), Teeple (2008), and references cited in these papers. - That said, it should be kept in mind that an approach in terms of (something like) ExP is not the only possibility. There are various other ways of setting up competitions of the type in tableaux 1-3 below. For instance, one could dispense with ExP by simply assuming that the input contains only a stem that is equipped with fully specified morpho-syntactic features, and that the competing outputs produced by GEN on the basis on this input are concatenations of the stem with some case marker. Such an approach would work just as well; but one would have to stipulate that the presence of the case exponent in the output as such does not give rise to a DEP violation (even if the exponent is not yet part of the input), and one would also have to come up with some appropriate definition of candidate sets that does not solely rely on input identity (as is standardly assumed: exactly those outputs compete with each other that go back to the same input); e.g., outputs with no inflectional exponent, or outputs with another type of inflectional exponent - say, a verbal ending -, must not compete. See Heck et al. (2002) for discussion of the issues arising with respect to candidate sets and input identity in all optimality-theoretic systems that involve structure-building (rather than just structure-modifying) operations, like syntax and morphology. Another alternative would be to assume that the input is a syntactic structure and the competing outputs represent different morphological realizations of the functional heads of these structures, as in Trommer (2001). Again, the present analysis could easily be rephrased in such an approach. I will refrain from doing this here because it presupposes that inflectional morphology is post-syntactic, an issue that is orthogonal to my concerns here.

${ }^{16} \mathrm{MATCH}$ is undominated throughout. One might argue that it would be problematic from a conceptual point of view to assume that it may ever be ranked below a faithfulness constraint for morpho-syntactic features. If so, this might indicate that MATCH is actually a property of GEN, hence systematically inviolable.

${ }^{17}$ The idea of holding faithfulness constraints that are relativized to morpho-syntactic features responsible for what is derived by the Subset Principle's specificity requirement in non-optimality theoretic approaches can be traced back to Grimshaw (2001) and Trommer (2001). I adapt this general procedure to an underspecification-free approach.

${ }^{18}$ As noted before, many underspecification-based approaches determine specificity by invoking a feature hierarchy (see Lumsden (1992), and Noyer (1992), among others; also see the feature-geometric approach in Harley \& Ritter (2002)); these hierarchies are sometimes viewed as universal (although there is little agreement in the literature as to what exactly the universal hierarchy should look like). As it stands, the present approach envisages a free re-ranking among the IDENT constraints; thus, there is no inherent reason why, say, IDENTOBL should outrank IDENTGov; the situation might easily be reversed, which would simply produce a different (though related) grammar on the basis of the same inventory of markers. However, it is worth pointing out that this does not mean that one could not adopt fixed hierarchies in an optimality-theoretic setting; a fixed ranking of the relevant faithfulness constraints could 
be effected via means like harmonic alignment and local conjunction (see Aissen $(1999,2002)$ ). Since it is unclear whether such an approach would be empirically well motivated, I will refrain from pursuing it here.

${ }^{19} \mathrm{~A}$ remark on notation: If a feature is set in italics, here and in the tableaux that follow, this is supposed to indicate that the value of the feature given here is that of the input specification of the exponent, and that this value has in fact been altered in the output so as to correspond to the stem's feature specification (triggered by $\mathrm{MATCH}$ ). Thus, say, "[+gov]" of $\mathrm{O}_{5}$ signals that a [+gov] specification on the exponent in the input has been changed to a [-gov] specification on the exponent in the output.

${ }^{20}$ Versions of the other eight exponents that involve unchanged feature specifications are not listed here. In what follows, I will abstract away from candidates that violate MATCH in tableaux because these candidates can never become optimal.

${ }^{21}$ Note incidentally that $\mathrm{O}_{6}$ incurs two faithfulness violations, which is more than the number of constraint violations induced by some of its suboptimal competitors $\left(\mathrm{O}_{2}, \mathrm{O}_{7}\right)$.

${ }^{22}$ See footnote 15 on systematic type mismatches like these, and possibilities of avoiding them; also compare the reconstruction of this approach in terms of ExP below.

${ }^{23}$ This problem could in principle be avoided if $\mathrm{O}_{3}=s i$ were specified for third person as a lexical property; Grimshaw does not envisage this as a possibility because it would raise problems for her account of spurious se effects.

${ }^{24}$ As it stands, Grimshaw's (2001) analysis involves undespecification of outputs, but not underspecification of inputs. However, it is not quite clear to me where the competing underspecified output exponents come from if they are not part of the input. As it stands, it would seem that GEN inserts them out of nowhere. One might argue that the simplest assumption in view of this would be that underspecified exponents are also in the input, together with the complete morpho-syntactic specification against which they are matched. If so, the conclusion must be that there is underspecification in the input in this approach as well, which would make the approach subject to the pertinent counter-argument mentioned above in subsection 2.2 - Note incidentally that McCarthy $(2002,81)$, in his concise reconstruction of Grimshaw's analysis, does not invoke underspecification at all. Here, syncretism is assumed to be derivable from constraint-driven neutralization of differences between fully specified inputs in the feature system. The analysis is not carried out in detail, but would seem to dispense with underspecification of exponents. (McCarthy $(2002,186$, fn. 8) remarks that he has "altered and simplified [Grimshaw's] discussion considerably.)

${ }^{25}$ To enhance overall coherence, I adapt the morpho-syntactic gender and case features of Grimshaw's analysis to the system of decomposed features of sections 1. and 2. above; this is mainly a matter of notation. Thus, the binary feature $[ \pm$ fem $]$ encodes the two genders, and $[+$ gov, \pm obl] captures accusative and dative case. As for person, I assume that a cross-classification of $[ \pm 1, \pm 2]$ derives the three instantiations of this grammatical category in Italian. (Irrelevantly, $[ \pm$ refl] replaces $[ \pm R]$.) As is the case with (10), some of the decisions taken here with respect to the 'basic' morpho-syntactic specifications of exponents are arbitrary (see section 4 below). Eventually, the input specifications of the clitics that give rise to syncretism would have to be supported by grammar-external evidence.

${ }^{26}$ This is not the only possible ranking, however. Some other rankings in which IDENTPERS is undominated would also work.

${ }^{27}$ As was the case with determiner inflection in German, let me emphasize that the goal here is to reconstruct an existing optimality-theoretic analysis in a framework that does not envisage underspecification; the goal is not to come up with the best possible analysis of the phenomenon. Note also that, as in Grimshaw's original approach, something extra must be said to derive the paradigmatic gap in (16); see footnote 40 below.

${ }^{28}$ Unlike Grimshaw's $\mathrm{T}_{4}, \mathrm{~T}_{6}$ lists all relevant candidates.

${ }^{29}$ On this view, the structure of a clitic pronoun in Romance is actually Stem-ExP, which may show 
up as, e.g., Ø-lo. A different fine structure for Romance clitics is proposed in Halle \& Marantz (1994).

${ }^{30}$ Grimshaw's (2001) analysis is ultimately more ambitious since it aims to derive not only the inventory of Romance object clitic systems, but also aspects of their syntactic distribution. In this context, Grimshaw argues that the phenomenon of spurious se in Spanish can be given a natural and simple account. The empirical observation is that in Spanish double object constructions with two object clitics (dative and accusative), the dative argument does not show up in the expected form (as le); rather, the reflexive clitic se is chosen. Grimshaw argues that this can be traced back to high-ranked alignment constraints: CAseRight and PersRight. Neither CAseRight nor PersRight can be satisfied in combinations with two clitics if the clitics are specified for case or person; and in Grimshaw's analysis, this is indeed the case for all clitics except for se (see the list in (17); the Spanish object clitic inventory is assumed to be similar). So, given that these two alignment constraints are ranked high, se will be selected because it is underspecified with respect to case and person. This does not yet account for the fact that it is the dative clitic that must go, not the accusative clitic (CASERIGHT and PERSRIGHT can be satisfied if one of the two person/case-specified clitics is replaced with se, no matter which one). Here Grimshaw suggests that there is an independently motivated hierarchy of markedness constraints that prefers accusative over dative. - More generally, Grimshaw's analysis of spurious se is in certain respects similar to impoverishment analyses as they are proposed in Bonet $(1991,1995)$ and Halle \& Marantz (1994). In these latter analyses, morpho-syntactic features that are required for the realization of the dative clitic are deleted in double object clitic contexts in Spanish, which effects a retreat to the general case - the underspecified clitic se. The impoverishment effect is brought about by the case/person alignment constraints in Grimshaw's analysis.

Such an account of spurious se cannot be given in the present analysis because it relies on underspecification (of $s e$ ). The question arises of whether the present approach can offer an alternative. Since I am mainly concerned with the derivation of syncretism in inflectional paradigms (i.e., inventories) in this paper, a thorough discussion of morpho-syntactic interface phenomena like spurious se is beyond the scope of the present investigation (choice of se over an otherwise expected dative clitic le is clearly dependent on the syntactic context, and it is only the "otherwise expected" exponents that I am concerned with here). That said, there is a straightforward possibility of transferring Grimshaw's approach: Instead of CASERIGHT or PERSRIGHT, the high-ranked alignment constraint would be something like NonReflRight. This forces all [-refl]-marked items to be right-peripheral in the clitic cluster, which invariably leads to a dilemma if both object clitics are specified as [-refl]. This will lead to a selection of the only non-[-refl]-marked item: se.

${ }^{31}$ See Wurzel (1984), Corbett \& Fraser (1993), and Müller (2004) for critical discussion of this reanalysis of case exponents in terms of stem alternation; but also see Bermúdez-Otero (2008b) for a recent defense of the idea.

${ }^{32}$ Again, since my only goal is to reconstruct an existing underspecification-based analysis within an approach that does without underspecification, the linguistic plausibility of the analysis is not at issue. See Corbett \& Fraser (1993), Halle (1994), Müller (2004), Wiese (2004), and Bailyn \& Nevins (2008) for alternative approaches to Russian declension in general, and the accusative/genitive syncretism in animacy-conditioned environments in particular.

${ }^{33}$ Note that that the Russian genitive shows up as a structural case with nouns, and under negation with verbs. This motivates its classification as an [-obl] case. The genitive specification adopted here for Russian is different from the one postulated by Bierwisch and Wiese for German; see section 1. above. In the worst case, this might simply reflect an incompatibility of the analyses - an issue that is orthogonal to my main goal here, which, as noted, is to reconstruct (in a coherent and maximally uniform way) individual underspecification-based analyses of a certain type in an optimality-theoretic approach that does without underspecification. Alternatively, the underlying feature specifications for "genitive" in Russian and German might indeed be significantly different; given the substantial differences 
in distribution between the genitive in Russian and the genitive in German, I take this second possibility to be a realistic option.

${ }^{34}$ If there is a case specified as [-obl-,-gov,--subj] in Russian, this ranking makes sure that its exponent cannot spread to the accusative gap. (The (or $a$ - see above) locative might be a potential candidate.)

${ }^{35}$ The ranking of IDENTOBL cannot be determined by the markers discussed in the present context because this constraint is not violated by spreading from either nominative or genitive. The feature $[ \pm \mathrm{obl}]$ is mainly needed to separate dative (which is [+obl]) from accusative (which is [-obl]). To exclude spreading of a dative form to the empty accusative cell, it must be ensured that IDENTOBL outranks IDENTSuBJ. No crucial ranking is established for IDEnTOBL and IDEnTGov yet; I assume the former to outrank the latter here, but this is inconsequential as long as no other paradigmatic gaps in the Russian case system come under scrutiny.

${ }^{36}$ Technically, however, this would be a case of feature-changing impoverishment, rather than simple deletion. See Noyer (1998).

${ }^{37}$ The fact that the constraints applying to stems outrank the constraints applying to exponents for what looks like systematic reasons might ultimately be taken as an argument in support of a cyclic concept of optimization, with stem optimization preceding optimization of the whole word form; see Kiparsky (2000), Itô \& Mester (2002), and Bermúdez-Otero (2008a), among others.

${ }^{38}$ The feature change in the output is indicated by placing the modified feature specification next to the stem. (Of course, there are many more candidates violating stem faithfulness, but we need not consider those here.)

${ }^{39}$ Note that no IDENTSTEM violations are signalled with $\mathrm{O}_{6}-\mathrm{O}_{10}$ here because the only IDENTSTEM constraint that these outputs violate is $\operatorname{IDENTGOv}(C l 2, S g)$, which has been singled out as a separate constraint.

${ }^{40}$ At this point, it may be useful to say something about how true paradigmatic gaps can be accounted for. Existing approaches often locate the source of these gaps outside the morphological component proper (e.g., in other grammatical domains where the use of certain forms may be blocked; see Halle (1973), Fanselow \& Féry (2002)), or attempt to reduce them to speaker-based uncertainties concerning lexical items and whether to apply morphophonological rules to them (see Albright (2003)). Trommer (2001, ch. 4), Wunderlich (2001b), and Rice (2005) develop accounts of paradigmatic gaps that are intrinsically optimality-theoretic. In general, versions of all these approaches are compatible with the analyses developed above. Suppose first that we follow Halle (1973), Fanselow \& Féry (2002), or Albright (2003) in assuming that the source of the gap lies outside the paradigm as such; then there is virtually nothing that needs to be said in addition. For instance, following Halle (1973), one might simply stipulate that some forms that are determined by the optimality-theoretic mechanism as optimal for a given paradigm cell are then assigned some diacritic (like [-lexical insertion], in Halle's terminology) which simply make them unusable in syntax. Alternatively, one might want to reconcile optimality-theoretic accounts of paradigm gaps with the proposal I have developed. Consider first Rice's (2005) system. Here, exceptional gaps are identified as those where the optimal form would violate very highly ranked phonological constraints (e.g., those prohibiting hiatus), and in those cases, the null parse may win. For concreteness, consider an abstract example based on determiner inflection in German. Suppose (counterfactually) that there were a determiner stem ending in /r/ (e.g., dier as a version of dies), and that a co-occurrence of this stem-ending / r/ with an optimal inflection marker /r/ (as determined by the morpho-syntactic IDENT constraints) would invariably lead to violations of higher-ranked phonological constraints (that block [r-r] configurations, epenthesis as in [r-V-r], deletion as in $[\mathrm{r}]$, and the like); in that case, a null parse may become optimal, leading to a true paradigmatic gap.

Note that Halle's and Rice's approaches are similar in that they can be integrated with the present approach in such a way that an optimal output of the morphological component (i.e., the filler of some paradigm cell) is subsequently filtered out. In contrast, the optimality-theoretic analyses in Trommer 
(2001, ch. 4) and Wunderlich (2001b) also envisage the possibility that some paradigmatic gaps might arise directly in the morphological component. For these cases, they postulate high-ranked markedness constraints excluding the outputs that would otherwise be expected to be optimal; then, another candidate may win that is either the null parse, or that has some radically different properties that make it look like it does not belong to the same paradigm anymore. To see how this might work, consider again a non-existing variant of the system of German determiner inflection, this time one in which a determiner like dies (say, dies') does not have any feminine forms in the oblique cases. In the system developed here, this could be handled by assuming a high-ranked markedness constraint * ${ }^{*} s^{\prime}-[-$ mask, + fem, + obl]; in interaction with a (slightly) lower-ranked constraint $* \varnothing$ and high-ranked constraints stems demanding stem faithfulness, this will let the null parse win in the relevant contexts (and only there), given that the null parse never violates faithfulness constraints.

${ }^{41}$ Three remarks on the potential access to decomposed morpho-syntactic features in syntax. First, one might speculate that decomposed features like [+dat], [+gov] correspond to two separate functional categories that are involved in case valuation/checking in the syntax; see, e.g., Starke (2006), and Caha (2008) for such a nanosyntatic approach. However, there seems to be little evidence for such a fine-grained syntactic structure outside of morphological considerations.

Second, it has recently been argued that syntax must in fact in some cases be able to handle underspecified morpho-syntactic information; see Keine (2010) on various exceptional agreement phenomena arising in the context of, i.a., differential argument encoding in Hindi, so-called "excentric" agreement in Basque and Itelmen, and global case splits in Yurok and Umatilla-Sahaptin, and Watanabe (2009) on the non-occurrence of agreement with subjects with higher numerals in languages like Czech. However, notwithstanding the general option of reanalysing the relevant data withoung invoking the idea of underspecification in syntax, the fact that all these cases appear exceptional to some degree might be taken to indicate that, as a rule, syntax does indeed not access underspecified feature information.

Third, Boguslavskaja (1995) reports that the choice of inflectional marker for a prenominal adjective or a prenominal genitive in Bezhta is determined by the case feature of the head noun. Crucially, all oblique cases (like ergative, locative) trigger one kind of prenominal marker (e.g., genitive 1), and the non-oblique case absolutive triggers another one (e.g., genitive 2). At first sight at least, this looks like a case of underspecified information (viz., [+obl]) being part of a syntactic (case assignment) rule. However, this state of affairs may plausibly be reinterpreted in such a way that the rule in question applies to (fully specified) absolutive case information, and case assignment with all other contexts is simply the default. If so, no recourse to underspecified case information is necessary in Bezhta. (Thanks to Greville Corbett (p.c.) for bringing the phenomenon to my attention, and for pointing out the possible solution; also see Corbett (2006).)

${ }^{42}$ However, Bierwisch's (1967) and Wunderlich's (1997a) analyses rely on disjunctions in marker specifications; strictly speaking, each disjunction can be viewed as a shorthand notation for an additional marker entry.

${ }^{43}$ Recall, though, that Wiese (1999) does not envisage this as a possibility.

${ }^{44}$ Irrelevant candidates that fatally violate IDENTMASC or IDENTOBL are omitted here; - stands for the wrong winner that the optimization procedure predicts.

${ }^{45}$ Strictly speaking, the constraint IDENTGov $(C l 2, S g)$ that was used in the reconstruction of Wunderlich's (2004) analysis above in order to ensure that there is no spreading of the nominative exponent in inanimate accusative class 2 environments already belongs in this class. Still, the case is slightly different because IDENTGOV $(C l 2, S g)$ is a constraint on stems, not a constraint on exponents.

${ }^{46} \mathrm{~A}$ second possibility (that I will not pursue here) might be to make use of constraint conjunction, as in Legendre et al. (1998) and Smolensky (2006). Yet another option (that I will also not discuss any further here) might be to make the faithfulness constraints sensitive to feature/feature-value combinations (rather than just features, irrespective of the values, as in the present approach); thus, there could be 
a constraint IDENT[-FEM], and another constraint IDENT[+FEM], which would have to be freely ranked with respect to one another, and with respect to other constraints.

${ }^{47}$ Similarly, in overspecification-based approaches that rely on a Superset (rather than a Subset) Principle (see Starke (2006), Caha $(2007,2008)$ ), the elsewhere distribution of /are/ can be derived by assuming it to be the most specific marker, as in (i) (from Caha (2007)).

(35) Overspecification approach:

a. $/ \mathrm{am} / \leftrightarrow[$ pres,part $]$

b. $\quad /$ is $/ \leftrightarrow[$ pres]

c. $\quad /$ are $/ \leftrightarrow[$ pres,part,addr,group]

${ }^{48}$ Then again, it is perhaps not inconceivable that the plural form is specified as $[-1,+2,+\mathrm{pl}]$, and then spreads into other persons in the plural; and some additional rule (or high-ranked constraint) of referral ensures that 2. person plural forms are used in 2. person singular contexts, overriding the expected spreading from 1. or 3. person singular. Such a view might be supported by the fact that there is an identity of 2. singular and 2. plural forms in English throughout, i.e., also including pronouns.

${ }^{49}$ For instance, no recourse to existing word forms and their properties would be necessary, in contrast to what is the case for the Elsewhere Learner, which needs access to global memory (or some related concept); see Pertsova (2007, 130).

${ }^{50}$ What about paradigms where it has been argued that underspecification alone does not suffice to capture all instances of syncretism? Many such cases are discussed in Stump (2001). One phenomenon that has received some attention is the pronoun declension of North Saami; cf. (i).

\begin{tabular}{|l||c|c|}
\hline & sg & pl \\
\hline \hline nom & gii & gea-t \\
\hline acc/gen & gea-n & gea-id \\
\hline loc & gea-s & gea-inna \\
\hline com & gea-inna & gea-iguin \\
\hline
\end{tabular}

Here it looks as though the syncretism involving comitative singular and locative plural in the nominal declension system of (the Eastern Finnmark variety of) North Saami involves an "unnatural class", and therefore requires a different treatment (see Baerman (2005a,b) and Hansson (2007)). However, upon closer inspection (i) turns out to be derivable in an underspecification approach after all; this has been shown in Alexiadou \& Müller (2008). Similar conclusions hold for some (but far from all) of the relevant paradigms that are discussed in Stump (2001), and addressed there by other means (simple rules of referral, pairs of rules of referral induced by the Bidirectional Referral Principle, and the Symmetrical Syncretism Metarule): Closer scrutiny reveals that they can often also be analyzed by invoking underspecification. However, few proponents of underspecification-based approaches would claim that underspecification can - or should - account for all cases of syncretism. In Distributed Morphology, e.g., impoverishment is available in addition; as seen above, Minimalist Morphology also envisages feature deletion; and both operations are roughly comparable to rules of referral in their effects. On the other hand, few proponents of, say, rules of referral would go so far as to claim that underspecification plays no role in analyses of syncretism - as noted at the outset of this article, there is underspecification in abundance in Paradigm Function Morphology, Network Morphology, A-Morphous Morphology, etc. Thus, the question is not whether underspecification is to be abandoned in favour of rules of referral, or vice versa - the question is where to put the emphasis.

All that said, given that the leading-form approach developed here is (in its pure form) somewhat less powerful, it is clear that more instances of syncretism will have to be left unresolved (or accounted for by different means) than in an underspecification-based approach. The Saami evidence, for instance, 
is not straightforwardly derivable in a leading-form approach (unless, of course, means like contextual faithfulness are adopted, which they may well be).

${ }^{51}$ See Clahsen (2006) for a possible exception. Clahsen reports on a priming study in favour of underspecification which, however, I take to be inconclusive since it abstracts away from phonology as the possible source of marker priming.

${ }^{52}$ For instance, it might turn out that the initial recognition of leading form exponents can be a complicated task in those cases where two (or more) environments exhibit a similar prominence (or frequency) in the child's input. In response to this, one could then assume that the child at first postulates as many separate exponents (form-content pairs) as there are environments. Driven by the Syncretism Principle, it would subsequently abandon separate exponents that can be traced back to other exponents that have been identified as leading forms, with the latter violating (appropriately demoted) faithfulness constraints. In effect, this would imply abandoning input optimization in favour of the Syncretism Principle.

\section{References}

Aissen, Judith (1999): Markedness and Subject Choice in Optimality Theory, Natural Language and Linguistic Theory 17, 673-711.

Aissen, Judith (2002): Bidirectional Optimization and the Problem of Recoverability in Head Marking Languages. Ms., University of California, Santa Cruz.

Albright, Adam (2003): A Quantitative Study of Spanish Paradigm Gaps. In: R. Billerey \& B. D. Lillehaugen, eds., WCCFL 22 Proceedings. Cascadilla Press, Somerville, MA, pp. $1-14$.

Albright, Adam (2008): Inflectional Paradigms Have Bases Too. Arguments from Yiddish.. In: A. Bachrach \& A. Nevins, eds., The Bases of Inflectional Identity. Oxford University Press, Oxford.

Alexiadou, Artemis \& Gereon Müller (2008): Class Features as Probes. In: A. Bachrach \& A. Nevins, eds., Inflectional Identity. Oxford University Press, Oxford, pp. 101-155. Anderson, Stephen (1992): A-Morphous Morphology. Cambridge University Press, Cambridge.

Aronoff, Mark (1994): Morphology by Itself. MIT Press, Cambridge, Mass.

Artstein, Ron (1998): The Incompatibility of Underspecification and Markedness in Optimality Theory. In: RuLing Papers. Vol. 1, Working Papers from Rutgers University, New Brunswick, New Jersey, pp. 7-13.

Baerman, Matthew (2005a): Directionality and (Un)Natural Classes in Syncretism, Language $80,807-824$.

Baerman, Matthew (2005b): The Limits of Morphological Underspecification. Ms., University of Surrey.

Baerman, Matthew (2009): Inflection Classes Through Profligate Syncretism?. Ms., University of Surrey. Talk at Workshop on Polyfunctionality and Underspecification, Leucorea.

Baerman, Matthew, Dunstan Brown \& Greville Corbett (2005): The Syntax-Morphology Interface. A Study of Syncretism. Cambridge University Press, Cambridge. 
Bailyn, John Frederick \& Andrew Nevins (2008): Class Features as Probes. In: A. Bachrach \& A. Nevins, eds., Inflectional Identity. Oxford University Press, Oxford, pp. 237-270.

Bakovic, Eric (2003): Vowel Harmony and Stem Identity, San Diego Linguistic Papers $1,1-42$.

Beckmann, Jill (1998): Positional Faithfulness. PhD thesis, University of Massachusetts, Amherst.

Bermúdez-Otero, Ricardo (2008a): Stratal Optimality Theory. Book Ms., University of Manchester. To appear: Oxford University Press.

Bermúdez-Otero, Ricardo (2008b): A Tutorial on Lexical Classes. Ms., University of Manchester. Talk, Workshop on Theoretical Morphology (WoTM 4), Großbothen 2008. Bierwisch, Manfred (1967): Syntactic Features in Morphology: General Problems of SoCalled Pronominal Inflection in German. In: To Honor Roman Jakobson. Mouton, The Hague/Paris, pp. 239-270.

Blevins, James (1995): Syncretism and Paradigmatic Opposition, Linguistics and Philosophy $18,113-152$.

Blevins, James (2004): Inflection Classes and Economy. In: G. Müller, L. Gunkel \& G. Zifonun, eds., Explorations in Nominal Inflection. Mouton de Gruyter, Berlin, pp. 51-95.

Bobaljik, Jonathan (2002): Syncretism without Paradigms: Remarks on Williams 1981, 1994. In: G. Booij \& J. van Marle, eds., Yearbook of Morphology 2001. Kluwer, Dordrecht, pp. 53-85.

Bobaljik, Jonathan (2008): Paradigms (Optimal and Otherwise): A Case for Skepticism. In: A. Bachrach \& A. Nevins, eds., Inflectional Identity. Oxford University Press, Oxford.

Boguslavskaja, Ol'ga (1995): Genitives and Adjectives as Attributes in Daghestanian. In: F. Plank, ed., Double Case: Agreement by Suffixaufnahme. Oxford University Press, Oxford and New York, chapter 6, pp. 230-239.

Bonet, Eulália (1991): Morphology after Syntax. PhD thesis, MIT, Cambridge, Mass.

Bonet, Eulalia (1995): Feature Structure of Romance Clitics, Natural Language and Linguistic Theory 13, 607-647.

Caha, Pavel (2007): The Shape of Paradigms. Ms., University of Troms $\varnothing$.

Caha, Pavel (2008): The Case Hierarchy as Functional Sequence. In: M. Richards \& A. Malchukov, eds., Scales. Vol. 86 of Linguistische Arbeitsberichte, Universität Leipzig, pp. $247-276$.

Carstairs-McCarthy, Andrew (2008): System-Congruity and Violable Constraints in German Weak Declension, Natural Language and Linguistic Theory 26, 775-793.

Clahsen, Harald (2006): Linguistic Perspectives on Morphological Processing. In: D. Wunderlich, ed., Advances in the Theory of the Lexicon. Mouton de Gruyter, Berlin, pp. 355-388.

Corbett, Greville (2006): Agreement. Cambridge University Press, Cambridge. 
Corbett, Greville (2007): Deponency, Syncretism, and What Lies Between. In: M. Baerman, G. Corbett, D. Brown \& A. Hippisley, eds., Deponency and Morphological Mismatches. Oxford University Press (for The British Academy), Oxford, pp. 21-43.

Corbett, Greville \& Norman Fraser (1993): Network Morphology: A DATR Account of Russian Nominal Inflection, Journal of Linguistics 29, 113-142.

Di Sciullo, Anna Maria \& Edwin Williams (1987): On the Definition of Word. MIT Press, Cambridge, Mass.

Don, Jan \& Elma Blom (2006): A Constraint-Based Approach to Morphological Neutralization. In: Linguistics in the Netherlands 2006. Benjamins, Amsterdam, pp. 78-88.

Eisenberg, Peter (2000): Grundriß der deutschen Grammatik. Band 1: Das Wort. Metzler, Stuttgart.

Embick, David (2003): Locality, Listedness, and Morphological Identity, Studia Linguistica 57, 143-169.

Fanselow, Gisbert (1991): Minimale Syntax. Habilitation thesis, Universität Passau.

Fanselow, Gisbert \& Caroline Féry (2002): Ineffability in Grammar. In: G. Fanselow \& C. Féry, eds., Resolving Conflicts in Grammars. Buske, Hamburg, pp. 265-307.

Frampton, John (2002): Syncretism, Impoverishment, and the Structure of Person Features. In: M. Andronis, E. Debenport, A. Pycha \& K. Yoshimura, eds., Papers from the Chicago Linguistics Society Meeting. Vol. 38, Chicago, pp. 207-222.

Gallmann, Peter (2004): Feature Sharing in DPs. In: G. Müller, L. Gunkel \& G. Zifonun, eds., Explorations in Nominal Inflection. Mouton de Gruyter, Berlin, pp. 121-160.

Grimshaw, Jane (2001): Optimal Clitic Positions and the Lexicon in Romance Clitic Systems. In: G. Legendre, J. Grimshaw \& S. Vikner, eds., Optimality-Theoretic Syntax. MIT Press, Cambridge, Mass., pp. 205-240.

Halle, Morris (1973): Prolegomena to a Theory of Word Formation, Linguistic Inquiry $4,3-16$.

Halle, Morris (1994): The Russian Declension: An Illustration of the Theory of Distributed Morphology. In: J. Cole \& C. Kisseberth, eds., Perspectives in Phonology. CSLI Publications, Stanford, pp. 29-60.

Halle, Morris (1997): Distributed Morphology: Impoverishment and Fission. In: B. Bruening, Y. Kang \& M. McGinnis, eds., Papers at the Interface. Vol. 30, MITWPL, pp. 425-449.

Halle, Morris \& Alec Marantz (1993): Distributed Morphology and the Pieces of Inflection. In: K. Hale \& S. J. Keyser, eds., The View from Building 20. MIT Press, Cambridge, Mass., pp. 111-176.

Halle, Morris \& Alec Marantz (1994): Some Key Features of Distributed Morphology. In: A. Carnie, H. Harley \& T. Bures, eds., Papers on Phonology and Morphology. Vol. 21 of MIT Working Papers in Linguistics, MITWPL, Cambridge, Mass., pp. 275-288.

Hansson, Gunnar Ólafur (2007): Productive Syncretism in Saami Inflectional Morphology. In: I. Toivonen, D. Nelson \& W. Palmer, eds., Saami Linguistics. Benjamins, 
Amsterdam, pp. 91-135.

Harley, Heidi (2001): Lecture 11: Distributed Morphology. Halle \& Marantz \& Potawatomi Inflection. Ms., University of Arizona. Available from:

http://dingo.sbs.arizona.edu/ hharley/courses/ABRALIN/Lecture2Processes.pdf.

Harley, Heidi \& Elisabeth Ritter (2002): Person and Number in Pronouns: A FeatureGeometric Analysis, Language 78, 482-526.

Harley, Heidi \& Rolf Noyer (2003): Distributed Morphology. In: L. Cheng \& R. Sybesma, eds., The Second GLOT International State-of-the-Article Book. Mouton de Gruyter, Berlin, pp. 463-496.

Heck, Fabian, Gereon Müller, Ralf Vogel, Silke Fischer, Sten Vikner \& Tanja Schmid (2002): On the Nature of the Input in Optimality Theory, The Linguistic Review $19,345-376$.

Itô, Junko \& Armin Mester (2002): Lexical and Postlexical Phonology in Optimality Theory. In: G. Fanselow \& C. Féry, eds., Resolving Conflicts in Grammars: Optimality Theory in Syntax, Morphology, and Phonology. Buske, Hamburg, pp. 183-207. Special issue of Linguistische Berichte.

Itô, Junko \& Armin Mester (2004): Morphological Contrast and Merger: ranuki in Japanese. Ms., University of California, Santa Cruz (ROA 711).

Itô, Junko, Armin Mester \& Jaye Padgett (1995): Licensing and Underspecification in Optimality Theory, Linguistic Inquiry 26, 571-613.

Jakobson, Roman (1962a): Beitrag zur allgemeinen Kasuslehre. Gesamtbedeutungen der russischen Kasus. In: Selected Writings. Vol. 2, Mouton, The Hague and Paris, pp. 2371.

Jakobson, Roman (1962b): Morfologičeskije Nabljudenija. In: Selected Writings. Vol. 2, Mouton, The Hague and Paris, pp. 154-181.

Kager, René (1996): On Affix Allomorphy and Syllable Counting. In: U. Kleinhenz, ed., Interfaces in Phonology. Akademie Verlag, Berlin, pp. 155-171.

Keine, Stefan (2010): Case and Agreement from Fringe to Core. Impoverishment Effects on Agree. Linguistische Arbeiten, Mouton de Gruyter, Berlin.

Kiparsky, Paul (1973): 'Elsewhere' in Phonology. In: S. Anderson \& P. Kiparsky, eds., A Festschrift for Morris Halle. Academic Press, New York, pp. 93-106.

Kiparsky, Paul (2000): Opacity and Cyclicity, The Linguistic Review 17, 351-367.

Lahne, Antje (2007): Deriving Polarity Effects in Inflectional Morphology. In: J. Trommer \& A. Opitz, eds., 12 Many. Vol. 85 of Linguistische Arbeitsberichte, Universität Leipzig, pp. $1-22$.

Legendre, Géraldine, Paul Smolensky \& Colin Wilson (1998): When is Less More? Faithfulness and Minimal Links in Wh-Chains. In: P. Barbosa, D. Fox, P. Hagstrom, M. McGinnis \& D. Pesetsky, eds., Is the Best Good Enough?. MIT Press and MITWPL, Cambridge, Mass., pp. 249-289.

Lumsden, John (1992): Underspecification in Grammatical and Natural Gender, Linguis- 
tic Inquiry 23, 469-486.

Mascaró, Joan (1996): External Allomorphy as Emergence of the Unmarked. In: J. Durand \& B. Laks, eds., Current Trends in Phonology: Models and Methods. European Studies Research Institute, University of Salford, Salford, Manchester, pp. 473-483.

McCarthy, John (2002): A Thematic Guide to Optimality Theory. Cambridge University Press, Cambridge.

McCarthy, John (2005): Optimal Paradigms. In: L. Downing, T. Hall \& R. Raffelsiefen, eds., Paradigms in Phonological Theory. Oxford University Press, Oxford, pp. 170-210.

McCarthy, John \& Alan Prince (1994): The Emergence of the Unmarked: Optimality in Prosodic Morphology, Proceedings of the North East Linguistic Society 24, 333-379.

Müller, Gereon (2002): Remarks on Nominal Inflection in German. In: I. Kaufmann \& B. Stiebels, eds., More than Words: A Festschrift for Dieter Wunderlich. Akademie Verlag, Berlin, pp. 113-145.

Müller, Gereon (2004): A Distributed Morphology Approach to Syncretism in Russian Noun Inflection. In: O. Arnaudova, W. Browne, M. L. Rivero \& D. Stojanovic, eds., Proceedings of FASL 12. University of Ottawa.

Müller, Gereon (2005): Syncretism and Iconicity in Icelandic Noun Declensions: A Distributed Morphology Approach. In: G. Booij \& J. van Marle, eds., Yearbook of Morphology 2004. Springer, Dordrecht, pp. 229-271.

Müller, Gereon (2007a): Notes on Paradigm Economy, Morphology 17, 1-38.

Müller, Gereon (2007b): A Radically Non-Morphemic Approach to Bidirectional Syncretism. In: J. Trommer \& A. Opitz, eds., 12 Many. Vol. 85 of Linguistische Arbeitsberichte, Universität Leipzig, pp. 43-72.

Müller, Gereon (2008): A Review of "The Syntax-Morphology Interface. A Study of Syncretism" by Matthew Baerman, Dunstan Brown, and Greville G. Corbett, Word Structure 1, 199-232.

Noyer, Rolf (1992): Features, Positions, and Affixes in Autonomous Morphological Structure. PhD thesis, MIT, Cambridge, Mass.

Noyer, Rolf (1998): Impoverishment Theory and Morphosyntactic Markedness. In: S. Lapointe, D. Brentari \& P. Farrell, eds., Morphology and its Relation to Phonology and Syntax. CSLI, Palo Alto, pp. 264-285.

Ortmann, Albert (2002): Economy-Based Splits, Constraints and Lexical Representations. In: I. Kaufmann \& B. Stiebels, eds., More than Words: A Festschrift for Dieter Wunderlich. Akademie Verlag, Berlin, pp. 147-177.

Pertsova, Katya (2007): Learning Form-Meaning Mappings in Presence of Homonymy: A Linguistically Motivated Model of Learning Inflection. PhD thesis, UCLA, Los Angeles.

Rice, Curt (2005): Optimal Gaps in Optimal Paradigms, Catalan Journal of Linguistics 4, 155-170. Special issue on Morphology in Phonology, edited by Maria-Rosa Lloret and Jesus Jimenez (also on ROA: 781).

Sauerland, Uli (1996): The Late Insertion of Germanic Inflection. Generals paper, MIT. 
Smolensky, Paul (2006): Harmonic Completeness, Local Constraint Conjunction, and Feature Domain Markedness. In: P. Smolensky \& G. Legendre, eds., The Harmonic Mind. Vol. II, MIT Press, Cambridge, Mass., chapter 14, pp. 27-160.

Starke, Michal (2006): Nanosyntax Class Lectures. Ms., University of Troms $\varnothing$.

Sternefeld, Wolfgang (2006): Syntax. Stauffenburg, Tübingen. Two volumes.

Stump, Gregory (2001): Inflectional Morphology. Cambridge University Press, Cambridge.

Stump, Gregory (2007): A Non-Canonical Pattern of Deponency and Its Implications. In: M. Baerman, G. Corbett, D. Brown \& A. Hippisley, eds., Deponency and Morphological Mismatches. Oxford University Press (for The British Academy), Oxford, pp. 71-95.

Teeple, David (2008): Lexical Selection and Strong Parallelism. Ms., University of California, Santa Cruz (ROA 992.

Tesar, Bruce \& Paul Smolensky (2000): Learnability in Optimality Theory. MIT Press, Cambridge, Mass.

Trommer, Jochen (2001): Distributed Optimality. PhD thesis, Universität Potsdam.

Trommer, Jochen (2003): Participant Reduction and Two-Level Markedness. In: J. Spenader, A. Eriksson \& Ö. Dahl, eds., Variation within Optimality Theory. Proceedings of the Stockholm Workshop. Stockholm University, Department of Linguistics, pp. 102108.

Trommer, Jochen (2005): Markiertheit und Verarmung. Ms., Universität Leipzig. Presented at the Honorary Doctorate Colloquium for Manfred Bierwisch, Leipzig 2005.

Trommer, Jochen (2006): Person and Number Agreement in Dumi, Linguistics 44, 10111057.

Watanabe, Akira (2009): A Morphological Solution to Agreement Puzzles in Slavic. Ms., Tokyo University. (Talk at Mediterranean Morphology Meeting 7).

Weisser, Philipp (2007): Case Borrowing. In: J. Trommer \& A. Opitz, eds., 12 Many. Vol. 85 of Linguistische Arbeitsberichte, Universität Leipzig, pp. 23-41.

Wiese, Bernd (1999): Unterspezifizierte Paradigmen. Form und Funktion in der pronominalen Deklination, Linguistik Online 4. (www.linguistik-online.de/3_99).

Wiese, Bernd (2003a): Russian Noun Morphology and Underspecified Paradigms. Ms., IDS Mannheim.

Wiese, Bernd (2003b): Zur lateinischen Nominalflexion: Die Form-Funktions-Beziehung. Ms., IDS Mannheim. www.ids-mannheim.de/gra/personal/wiese.html.

Wiese, Bernd (2004): Categories and Paradigms: On Underspecification in Russian Declension. In: G. Müller, L. Gunkel \& G. Zifonun, eds., Explorations in Nominal Inflection. Mouton de Gruyter, Berlin, pp. 321-372.

Williams, Edwin (1994): Remarks on Lexical Knowledge, Lingua 92, 7-34.

Williams, Edwin (1997): Blocking and Anaphora, Linguistic Inquiry 28, 577-628.

Woolford, Ellen (2007): Aspect Splits as Contextual Faithfulness. Ms., University of Massachusetts, Amherst. 
Wunderlich, Dieter (1996): Minimalist Morphology: The Role of Paradigms. In: G. Booij \& J. van Marle, eds., Yearbook of Morphology 1995. Kluwer, Dordrecht, pp. 93-114.

Wunderlich, Dieter (1997a): Der unterspezifizierte Artikel. In: C. Dürscheid, K. H. Ramers \& M. Schwarz, eds., Sprache im Fokus. Niemeyer, Tübingen, pp. 47-55.

Wunderlich, Dieter (1997b): A Minimalist Model of Inflectional Morphology. In: C. Wilder, H.-M. Gärtner \& M. Bierwisch, eds., The Role of Economy Principles in Linguistic Theory. Akademie Verlag, Berlin, pp. 267-298.

Wunderlich, Dieter (2001a): A Correspondence-Theoretic Analysis of Dalabon Transitive Paradigms. In: G. Booij \& J. van Marle, eds., Yearbook of Morphology 2000. Kluwer, Dordrecht, pp. 233-252.

Wunderlich, Dieter (2001b): How Gaps and Substitutions Can Become Optimal: The Pronominal Affix Paradigms of Yimas, Transactions of the Philological Society 99(2), 315-366.

Wunderlich, Dieter (2004): Is There Any Need for the Concept of Directional Syncretism?. In: G. Müller, L. Gunkel \& G. Zifonun, eds., Explorations in Nominal Inflection. Mouton de Gruyter, Berlin, pp. 373-395.

Wurzel, Wolfgang Ullrich (1984): Flexionsmorphologie und Natürlichkeit. Akademie Verlag, Berlin.

$\mathrm{Xu}$, Zheng (2007): Inflectional Morphology in Optimality Theory. PhD thesis, Stony Brook University.

Zifonun, Gisela (2001): Grammatik des Deutschen im europäischen Vergleich: Das Pronomen, Teil 1: Überblick und Personalpronomen. Amades working paper 4/01, IDS Mannheim.

Zwicky, Arnold (1985): How to Describe Inflection. In: M. Niepokuj, M. V. Clay, V. Nikiforidou \& D. Feder, eds., Proceedings of the 11th Annual Meeting of the Berkeley Linguistics Society. BLS, Berkeley, University of California, pp. 372-386. 